\title{
Evaluation of Porous Cathodes for the Removal of Hazardous Species from Alkaline Waste Solutions
}

by

D. T. Hobbs

Westinghouse Savannah River Company

Savannah River Site

Aiken, South Carolina 29808

\section{RECEIVED}

JAN 301998

OSTI

This paper was prepared in connection with work done under the above contract number with the $U . S$. Department of Energy. By acceptance of this paper, the publisher and/or recipient acknowledges the U.S. Government's right to retain a nonexclusive, royalty-free license in and to any copyright covering this paper, along with the right to reproduce and to authorize others to reproduce all or part of the copyrighted paper. 


\section{DISCLAIMER}

This report was prepared as an account of work sponsored by an agency of the United States Government. Neither the United States Government nor any agency thereof, nor any of their employees, makes any warranty, express or implied, or assumes any legal liability or responsibility for the accuracy, completeness, or usefulness of any information, apparatus, product, or process disclosed, or represents that its use would not infringe privately owned rights. Reference herein to any specific commercial product, process, or service by trade name, trademark, manufacturer, or otherwise does not necessarily constitute or imply its endorsement, recommendation, or favoring by the United States Government or any agency thereof. The views and opinions of authors expressed herein do not necessarily state or reflect those of the United States Government or any agency thereof.

This report has been reproduced directly from the best available copy.

Available to DOE and DOE contractors from the Office of Scientific and Technical Information, P.O. Box 62, Oak Ridge, TN 37831; prices available from (615) 576-8401.

Available to the public from the National Technical Information Service, U.S. Department of Commerce, 5285 Port Royal Road, Springfield, VA 22161. 


\section{DISCLAIMER}

Portions of this document may be illegible electronic image products. Images are produced from the best available original document. 


\section{EVALUATION OF POROUS CATHODES FOR THE REMOVAL OF HAZARDOUS SPECIES FROM ALKALINE WASTE SOLUTIONS}

Final Report for

Task order \# 218

submitted to

Dr. David T. Hobbs

Westinghouse Savannah River Company

P.O. Box 616

Aiken, SC 29802

by

Kamal Jha, Haraldo A. Duarte and John W. Weidner

Department of Chemical Engineering

University of South Carolina

Columbia, SC 29208

July 31, 1997 


\begin{abstract}
This is the final report of the work that has been performed on task order \# 218 since the start of the task, July 19, 1996. The main conclusions of this research are: (1) no costeffective electrode material has been found to remove the hexavalent chromium from the alkaline waste stream; (2) nickel electrodes may efficiently reduce nitrate and nitrite in the presence of hexavalent chromium by alternating the electrodes polarity at regular intervals; (3) the preliminary conceptual design of the electrochemical treatment facility can process approximately 1.8 million gallons per year of low-level alkaline wastes containing $2.2 \mathrm{M}$ nitrate and $0.53 \mathrm{M}$ nitrite; and (4) a model of the nitrate and nitrite destruction using an undivided flow cell has been developed and kinetic parameters extracted to reasonably predict the experimental results for nitrate and nitrite reduction in presence of chromate. Experiments were performed to obtain the optimum operating procedure for reducing nitrate and nitrite in the presence of chromium using nickel electrodes and the alternating polarity technique.
\end{abstract}

\title{
Introduction
}

Treatment of high-level radioactive wastes at the Savannah River Site will result in the production of 150 million gallons of low-level alkaline wastes. These low-level wastes contain hazardous species such as nitrate, nitrite, chromate, heavy metals and long-lived radionuclides. Development of waste treatment technologies are needed to reduce the quantity of wastes requiring long-term storage. Previous studies ${ }^{1-4}$ have demonstrated the feasibility of electrochemical techniques to destroy nitrates and nitrites from the alkaline wastes. We concluded that the preliminary conceptual design of an electrochemical treatment facility can process approximately 1.8 million gallons per year of low-level alkaline wastes containing $2.2 \mathrm{M}$ nitrate and $0.53 \mathrm{M}$ nitrite. However, the effect of hexavalent chromium on the destruction of nitrates and nitrites must be resolved before the electrochemical treatment becomes a viable option. Previous studies ${ }^{5,6}$ have shown that the presence of chromate may decrease the electrochemical efficiency of the treatment process and thus decrease the rate at which the waste is processed. 
The electrochemical treatment facility must be able to take a waste stream containing hexavalent chromium and efficiently reduce the nitrate and nitrite. Two strategies were considered to deal with the chromate: (1) either reduce or remove the chromate from the waste stream before it is fed to the nitrate/nitrite reduction reactors; or (2) operate the nitrate/nitrite reduction reactors in a way which minimizes the passivating effects of hexavalent chromium reduction. Initially, the first strategy was the focus of this project since it was shown that in alkaline solutions, hexavalent chromium reduces and precipitates on the surface of the electrode ${ }^{7,8}$. Our studies have confirmed this phenomenon and the need for periodic regeneration of the electrode surface. Gold was found to be the most efficient electrode material for chromate reduction. The capacity of the gold electrode for reducing hexavalent chromium before it passivates is low, but an electrochemical oxidation step was able to regenerate the surface. Also the amount of chromate needed to form the passive film is only $10 \%$ of that reduced in each cycle. Carbon and steel electrodes could also be used to reduce the hexavalent chromium, but they cannot be regenerated electrochemically. A periodic chemical regenerative process (e.g., acid wash) would have to be implemented in order to use these electrodes. The prohibitive cost of gold electrodes and the impracticality of the frequent chemical regeneration step associated with carbon and steel make the first strategy for dealing with the chromate unattractive.

The focus of this project then turned to operating the nitrate/nitrite reduction reactors in a way that minimizes the passivation effects of chromate reduction. Some electrode materials we studied (e.g. nickel), do not efficiently reduce hexavalent chromium. For example, a long-term (15 hr, $10 \mathrm{~mA})$ experiment was performed with the nickel foam cathode and its results verified that a negligible change in moles of chromate occurred over the run. Further cyclic voltammetry study results on nickel confirmed that the hexavalent chromate reduction was negligible. However, when constant current experiments were done to reduce nitrate and nitrite in presence of chromate, the efficiencies for the reduction currents were drastically lower than those without chromate. Therefore, chromate has a significant effect on the nitrate and nitrite destruction. It is hypothesized that though it cannot be quantified, chromate does reduce enough to form 
the passive film on the electrode surface and hinder the nitrate/nitrite reduction reactions. However, a way to efficiently reduce nitrate and nitrite in presence of chromate was invented during this research. The method was to operate the cell by reversing the polarity of the nickel electrodes at regular intervals. The optimum switching time for the cell current was also found to minimize the passivating effect of the hexavalent chromate. An extra task (task 5) was added to include the details relevant to the new electrochemical procedure. Task 5 is presented in the article format submitted to the J. of Applied Electrochemistry.

\section{Report on Proposed Tasks}

\section{Task 1: Porous Electrode Evaluation}

\section{Task 1.1: Develop test plan and apparatus}

For the hexavalent chromium reduction studies, three types of experimental apparatus were used besides beaker experiments for cyclic voltammetry studies. For the initial flow cell experiments, which focussed on strategy of removing hexavalent chromate, the drip flow cell shown in Figure 1 was assembled. The cell had a porous nickel cathode and platinum gauge as anode. Due to the high ohmic resistances from the cathode to the anode, the flow-cell was used in the undivided configuration. The setup had the advantage of being operable with small electrolyte volume because no surge tanks and minimal piping were needed. Smaller volumes were needed to increase the accuracy of the measured chromate reduction rates. However, when no cost effective electrode material was found to efficiently reduce chromate, experiments in line with the second strategy i.e. efficiently reducing nitrate and nitrite in presence of chromate were performed. The experimental setup used for the majority of these experiments is shown in Figure 2. It consisted of a batch cell in undivided mode having planar nickel electrodes, and the timer and switching mechanism to alternate the polarity of the electrodes at specified timings. The polarity switching facility was used for the first time in the project 
with this setup. Details of the setup are given in Task 5. The conclusions from the experiments on the batch setup needed to be tested on an $\mathrm{MP}^{\dagger}$ cell because flow cells similar to the MP cell will be used in the actual process at Savannah River Site (SRS). Therefore, the last set of experiments were performed in the MP cell setup shown in Figure 3. The setup consisted of the MP cell, recirculation tank and a timing and relay switch for alternating the electrode polarity. The MP cell was operated in undivided mode with both electrodes being planar or porous. The configurations of the MP cell used in the experiments are shown in Figure 4. As shown, the porous electrodes were operated in the flow-through mode.

\section{Task 1.2: Identify optimum electrode materials}

\section{Cyclic Voltammetry Studies}

As a part of the evaluation of electrode materials, cyclic voltammetry experiments were performed on twelve electrode materials, eight of which were planar and four were porous. The materials tested along with their specifications are listed in Table 1. One set of cyclic voltammograms (CVs) was obtained in a solution of $1.33 \mathrm{M} \mathrm{NaOH}$ and another set was obtained in a solution of $0.015 \mathrm{M} \mathrm{K}_{2} \mathrm{Cr}_{2} \mathrm{O}_{7}$ and $1.33 \mathrm{M} \mathrm{NaOH}$. The difference in the currents between these two voltammograms was attributed to the presence of the hexavalent chromium. The potential was swept between the ranges where hydrogen and oxygen evolution occurred (approximately $-1.3 \mathrm{~V}$ and $0.8 \mathrm{~V}$, respectively, versus $\mathrm{Ag} / \mathrm{AgCl}$ reference electrode) and the sweep was started from the positive potential. The sweep rates for the electrodes are given in Table 1. All the planar electrodes were swept at a rate of $50 \mathrm{mV} / \mathrm{s}$. A sweep rate of $100 \mathrm{mV} / \mathrm{s}$ was also used for nickel electrode to enhance the peak heights of the reduction reactions occurring. A lower sweep rate $(10 \mathrm{mV} / \mathrm{s})$ was used for the porous electrode materials to compensate for the large surface area of the electrodes.

\footnotetext{
${ }^{\top}$ Multi-purpose electrochemical cell developed by Electrocell AB (Sweden).
} 
Summary of Cyclic Voltammetry Studies:

- The CVs on the gold electrode (see Figure 5) show a pattern closely resembling that reported in literature ${ }^{7}$. The hexavalent chromium reduction peak occurs at $-0.7 \mathrm{~V}$ (peak A) and the oxidation of the chromium hydroxide film is observed at $0.4 \mathrm{~V}$ (peak B). The relative areas under peaks A and B indicate that only $10 \%$ of the hexavalent chromium that is reduced results in a chromium hydroxide film. Therefore, approximately $90 \%$ of the chromate reduced probably dissolves in the electrolyte. The height of peak A remained fairly constant on cycling which suggests that the passive chromium hydroxide layer is completely removed during the anodic sweep (i.e., at peak B).

- Peaks for hexavalent chromium reduction could not be detected on nickel and platinum (see Figures 6 and 7, respectively). The peaks in Figure 6 are due to the redox reaction between $\mathrm{Ni}(\mathrm{OH})_{2}$ and $\mathrm{NiOOH}$. On platinum, a distinct peak for chromate reduction was hard to distinguish from the large cathodic background current resulting from the adsorption of hydrogen (i.e. current between -0.2 and -1.0 V). However, a peak resembling that of the oxidation of the chromium hydroxide film (peak B) was observed which suggests that some chromium(VI) reduction might be occurring.

- Some interesting results were found from CV studies on glassy carbon electrode (see Figure 8). A peak for the hexavalent chromium reduction was seen at $-1.0 \mathrm{~V}$ (peak A), although the peak height was a factor of 3 less than that observed on gold. The hydrogen evolution reaction was suppressed on this electrode and did not occur for a cathodic potential less than $2 \mathrm{~V}$, which suggests that high chromate reduction efficiencies can be obtained for a wide voltage range. However, the chromate reduction peak heights reduced progressively with each cycle. The reduction peak in the $10^{\text {th }}$ cycle was about one-third of that in the $2^{\text {nd }}$ cycle. Cycling to higher anodic potentials to oxidize the chromium film did not prevent the decrease in peak heights on 
cycling. This suggests that the passive hydroxide film is not completely removed during the anodic sweep. Re-polishing of the electrode was needed to fully remove the passive film.

- The CVs on the steel electrode (see Figure 9) indicated that chromate reduction occurred on the electrode material. The peak height for the chromate reduction however, varied with the cycle number. For example, the height for the $3^{\text {rd }}$ cycle was $50 \%$ less than that for the $2^{\text {nd }}$ cycle. A probable reason for this phenomenon is that the chromium film was not oxidized back as indicated from the absence of the oxidation peak.

- The CVs obtained on the copper foil (see Figure 10) showed peaks for different states of copper. Peaks for chromate reduction and the oxidation of the chromium hydroxide film were also observed. The peak current densities for the chromate reactions on copper were about 2 times that on the steel electrode.

- Negligible chromate reduction was found on the silver electrode (see Figure 11). However, the oxygen evolution was found to decrease considerably in the presence of chromate.

- Figures 12 and 13 show the CV results on graphite rod and porous vitreous carbon, respectively. The results obtained from either of these materials was similar. Evidence of chromate reduction was found and it occurred over a range of cathodic potentials ($0.8--1.5 \mathrm{~V})$. The chromate reduction current, however, decreased with cycle number as was found with the steel cathode. The absence of chromium hydroxide oxidation peak was also observed.

- Results from the studies on three TySar porous electrode materials are shown in Figures 14-16. The sweep rates for these studies was $10 \mathrm{mV} / \mathrm{s}$. The current densities are based on the electrode active area. No conclusive peaks for chromate reduction are seen in any of these materials. A small peak observed in the case of TySar SB 
(Figure 14) which was not present in the case of blank run (i.e. with only $\mathrm{NaOH}$ ), maybe due to chromate reduction. This peak is observed at a potential of $-0.6 \mathrm{~V}$ vs. $\mathrm{Ag} / \mathrm{AgCl}$ which is near the potential at which the reduction peaks were seen on the some of the planar electrodes, for example gold and glassy carbon (see Figures 5 and 8). The results obtained for TySar EP are similar to that obtained for planar platinum (see Figure 7).

Conclusions from Cyclic Voltammetry Studies

- Gold was found to be the most favorable electrode material for the hexavalent chromium reduction among the twelve materials tested. It's capacity was the highest and was approximately $90 \times 10^{-9} \mathrm{M} / \mathrm{cm}^{2}$ of reduced chromium per cycle. However, its prohibitive cost outweighs its favorable reduction capacity. Also electrochemical regeneration of the electrode would be needed periodically in order to efficiently reduce the chromate and this would add to the cost of the process.

- Glassy carbon, graphite, vitreous carbon, and steel cathodes show promise for hexavalent reduction but they may not be suitable for electrochemical regeneration. Acid wash may be needed for regeneration.

- Copper shows evidence of hexavalent chromium reduction. However, the presence of multiple peaks in the cyclic voltammogram on copper make it a complex electrode to study and pinpoint the processes related to chromate reduction. More studies need to be done before copper can be considered as a suitable electrode for chromate removal

- Nickel, silver, platinum, and the three TySar porous electrode materials were found to be relatively inert to the hexavalent chromium reduction reaction. The absence of peaks on these materials presented two possible scenarios: (1) there was no chromate reduction and therefore, no passivation of electrode surface; (2) there was a finite chromate reduction which is not detectable but may be enough to passivate the electrode surface. The nitrate/nitrite reduction would be affected if the second scenario were valid. 


\section{Task 1.3: Determine rate of chromate removal}

To determine the rate of change in moles of chromate when only chromate in alkaline media is used as the feed, a constant current experiment using the flow cell (shown in Figure 1) was performed under the following conditions:

Cell current : $10 \mathrm{~mA}$

Feed: $125 \mathrm{ml}$ of $0.001 \mathrm{M} \mathrm{K}_{2} \mathrm{Cr}_{2} \mathrm{O}_{7}$ in $1.33 \mathrm{M} \mathrm{NaOH}$

Electrode: porous nickel foam cathode

Flow rate: $2 \mathrm{ml} / \mathrm{min}$. approximately

Run Time: $15.5 \mathrm{hr}$.

The electrolyte was recirculated continuously and the potential between the cell potential and that between the cathode and the reference was monitored. The potential of the cathode vs. the reference potential was observed to be almost constant $(\sim 1.3 \mathrm{~V}$ vs. $\mathrm{Ag} / \mathrm{AgCl}$ reference). The electrolyte volume after the run was measured. Also, the concentration of the hexavalent chromium of the post run electrolyte was measured using the UV-VIS Spectrophotometer. The change in concentration indicated showed that only about $3 \%$ of the chromate moles were reduced over the $15 \mathrm{hr}$ run. The coulombs passed, however, were sufficient to reduce the chromate moles by 15 times if the reaction was $100 \%$ efficient. From these results the hexavalent chromium reduction appeared to occur at a very slow rate if at all on the nickel electrode. This result is consistent with the absence of a chromate reduction peak in the results from cyclic voltammetry studies performed on nickel (details in Task 1.2). Therefore, removal of hexavalent chromate using electrochemical reduction on nickel electrode is not feasible.

The above experiment was performed while operating the flow cell in the undivided mode. One of the drawbacks of this mode of operation is that some of the $\mathrm{Cr}(\mathrm{VI})$ reduced at the cathode to $\mathrm{Cr}(\mathrm{III})$ may get reoxidized back to $\mathrm{Cr}(\mathrm{VI})$ at the anode. Therefore, there might be some chromate reduction at the cathode, which would not be detected from 
accounting the net change in chromate moles. However, since the chromate reduction stops once the chromium hydroxide film is formed, the amount of chromate reduced and reoxidized would correspond to a negligible percentage of the chromate in the feed.

\section{Task 1.4: Determine the form of reduced species}

The cyclic voltammetric studies suggest that the coulombs used in the reduction of hexavalent chromium film are about 10 times that used in the oxidation of trivalent chromium hydroxide film (see peak A and B in Figure 5). Therefore, about $90 \%$ of the reduced chromate is soluble and probably exists as $\left[\mathrm{Cr}(\mathrm{OH})_{4}^{-}\right]$as claimed earlier in a past study $^{7}$.

An EQCM experiment (details given in Task 3.2) could not detect any mass changes during the reduction process. Calculations for the coulombs required to reduce the chromate and then anodically regenerate the gold electrode on the crystal in each cycle were done from the data in the cyclic voltammograms on the electrode. The results suggest that if all the hexavalent chromium reduced, resulted in film deposition, about 4 $\mu \mathrm{g}$ mass change would have been observed. However the calculation from the anodic peak area suggests that about $0.8 \mu \mathrm{g}$ mass change would have been observed. The equipment (EQCM) has a sensitivity of $1 \mu \mathrm{g}$ and it did not detect any mass change. This result is therefore, consistent with the conclusions from the cyclic voltammograms that almost all the chromium reduced stayed in the solution in the form of $\left[\mathrm{Cr}(\mathrm{OH})_{4}\right]$ instead of depositing as a chromium hydroxide $\left[\mathrm{Cr}(\mathrm{OH})_{3}\right]$ film.

Attempts were made to calibrate the Ion Chromatograph with the UV-VIS detector to measure the $\mathrm{Cr}$ (III) concentration and therefore, verify that the reduced chromium stayed in the solution. The procedures and reagents prescribed by the manufacturer were used. Unfortunately, peaks for $\mathrm{Cr}$ (III) could not be detected. However, detection of $\mathrm{Cr}$ (VI) was possible with the UV-VIS spectrophotometer and calibration curves for its measurement were made. Interaction studies to determine the effect of $\mathrm{Cr}(\mathrm{III})$ concentration on measurement of $\mathrm{Cr}(\mathrm{VI})$ concentration were also done and the results suggest that the former had a negligible effect . 


\section{Task 1.5: Determine the effective capacity of the electrode}

The ability of a porous electrode to remove chromate will cease when one of the two phenomena occur: (1) the growth of a passive layer prevents further reduction of hexavalent chromium; or (2) the pores of the electrode are filled with chromium hydroxide. The first one is a kinetic limitation of the process while the second is dependent on the pore dimensions and operating conditions such as flowrate. Results from the cyclic voltammetry studies described in Task 1.2, suggest that the kinetic limitation would be predominant in the chromate removal process. The mass of the passive film is negligible (e.g. $4 \mu \mathrm{g} / \mathrm{cm}^{2}$ for gold electrode) and therefore, insufficient to clog the pores of a porous electrode. The effective capacity of the electrodes can be calculated from the area under the reduction peaks in the cyclic voltammograms. The highest capacity obtained in the materials tested was for gold and it was about $90 \times 10^{-9}$ $\mathrm{M} / \mathrm{cm}^{2}$ of reduced chromium. The capacity of nickel electrode could not be quantified due to no peak observed in the cyclic voltammogram on nickel. However, from the standpoint of the operation of nickel electrodes, it was found (see task 5) that approximately 625 $\mathrm{C} / \mathrm{cm}^{2}$ of charge were required to remove the passive chromium hydroxide film and regenerate the electrode.

\section{Task 1.6: Identify method to remove chromium deposits from electrode}

The cyclic voltammetry studies (details in Task 1.2) suggested possible ways to remove the passive film from the different electrode surfaces and thus regenerate them. Among the materials which showed chromate reduction in the tests, gold and copper could be regenerated electrochemically by anodizing them to a potential greater than $0.5 \mathrm{~V}$ vs. $\mathrm{Ag} / \mathrm{AgCl}$ reference. The regeneration was almost complete after the anodization process as seen from the similar reduction peak areas in the different sweep cycles (see Figure 5 and 8). The electrochemical regeneration of the other electrodes showing chromate reduction (glassy carbon, graphite, vitreous carbon, and carbon steel), was not 
possible. However, since the capacity was regained in these electrodes after rinsing with $0.1 \mathrm{M} \mathrm{HCl}$, acid wash may be a probable regeneration procedure.

Electrochemical regeneration of nickel electrode was possible over long hours of usage $(500 \mathrm{hrs})$. The details of the regeneration of nickel are given in Task 5 . Complete regeneration was achieved by washing it with $0.05 \mathrm{M}$ oxalic acid solution.

\section{Task 1.7: Preliminary estimate of facility size}

Results from sub-tasks $1.2-1.5$ indicate that a facility to reduce or remove chromate is not practical.

\section{Task 2: Design Review}

The preliminary conceptual design of the electrochemical treatment facility for the electrochemical removal of nitrates and nitrites was evaluated nitrite (See Appendix I for details). The design is adequate to process between 1.7 and 2.3 million gallons per year (MM gpy) for a waste stream containing 1.68 to $2.2 \mathrm{M}$ of $\mathrm{NaNO}_{3}$ and 0.403 to $0.53 \mathrm{M}$ of $\mathrm{NaNO}_{2}$. For this range of concentrations, batch times between 39 to 51 hours were estimated. These processing times are based on 13,500-gallon batches and 274 days of electrolyzer operation. The power that is required to process the waste in the electrolyzer is 2.61 million watts. The electrolyzer energy requirement is 17.2 million $\mathrm{kW}$-hr/year. A controlled current scheme may be able to reduce the energy costs by using higher currents in the beginning of the batch and progressively lower the currents as the concentration of nitrates and nitrites is reduced.

\section{Task 3: Chromate Precipitation and Dissolution}

\section{Task 3.1: Develop Experimental Plan}

A preliminary experiment using the electrochemical quartz crystal microbalance (EQCM) was performed whose details are given in Task 3.2. Experiments using a batch cell to 
study the time for deposition and dissolution of the passive film were also performed and details are given in Task 5.

Task 3.2: Determine rate of chromate precipitation

To study the chromate reduction and the trivalent chromium hydroxide film deposition, an experiment was conducted using an electrochemical quartz crystal microbalance (EQCM). The EQCM is able to simultaneously measure mass, current, and potential during a reduction reaction (e.g. chromate reduction) resulting in film formation. A quartz crystal having a polished gold electrode was used in the experiment. The electrolyte was $50 \mathrm{ml}$ of $0.001 \mathrm{M} \mathrm{K}_{2} \mathrm{Cr}_{2} \mathrm{O}_{7}$ in $1.33 \mathrm{M} \mathrm{NaOH}$ and a constant current density of $5 \mathrm{~mA} / \mathrm{cm}^{2}$ was used. The experiment was performed for a period of 5 minutes and the equipment recorded no change in the mass. Calculations from the cyclic voltammogram on the electrode showed that the mass deposited would be about $0.8 \mu \mathrm{g}$ which is lesser than the sensitivity of the instrument. Therefore, the film formed by chromate reduction is too thin and light to be detected by the EQCM. Therefore, studies similar to earlier work on electrochemical precipitation of nickel hydroxide ${ }^{9,10}$ where film depositions in excess of $10 \mu \mathrm{g}$ occurred, cannot be performed with the chromate reduction.

Experiments were performed using a batch cell to study the effect of the passive chromium film on the nitrate and nitrite reduction. Though the rate of chromate precipitation could not be quantified, the optimum charge needed for dissolution of the film $\left(625 \mathrm{C} / \mathrm{cm}^{2}\right)$ was determined. Details of the study are listed in Task 5 .

Task 3.3: Determine rate of chromate dissolution

This task could not been performed due to the inability of the EQCM to measure the mass of the thin chromate films as mentioned earlier in Task 3.2. The results from the cyclic voltammetry studies described earlier, show that the coulombs used in the removal of the $\mathrm{Cr}(\mathrm{III})$ film is about $10 \%$ of the coulombs used in the $\mathrm{Cr}(\mathrm{VI})$ reduction. This implies that $90 \%$ of the chromate reduced stays in the solution in a soluble form of $\mathrm{Cr}$ (III) 
for example, $\left[\mathrm{Cr}(\mathrm{OH})_{4}^{-}\right]$. The results from the batch cell runs (see task 5 for details) suggest that there is an optimum charge that needs to be passed to regenerate nickel cathode. Approximately $625 \mathrm{C} / \mathrm{cm}^{2}$ needs to be passed to regenerate the cathode electrochemically. However, not all of this charge is used in the reoxidation of the chromium hydroxide film as a majority of it would be probably used up in oxygen production which occurs simultaneously and has much higher kinetics. Therefore, the rate of dissolution of the chromium film could not be determined.

\section{Task 4: Mathematical Model of Chromate Recovery}

A dynamic model of the undivided flow cell setup shown in Figure 3 was developed in Speedup ${ }^{\ddagger}$. The model was developed by modifying the divided cell boundary layer model of Prasad et $\mathrm{al}^{11}$. The main units in the model are: (1) an undivided cell, and (2) an electrolyte recirculation tank which also serves as a flash tank. Though the model has been developed for planar electrodes in the cell, an analogous model for both electrodes being porous can be similarly developed. The undivided cell has 5 reactions occurring at the cathode and two at the anode (oxygen evolution and nitrite oxidation). Therefore, it has one additional reaction at anode (the nitrite oxidation) compared to the divided cell. The concentration of nitrite at the anode surface is needed for calculating the nitrite oxidation current. The boundary layer theory is used to relate the surface concentration of nitrite to the bulk concentration value.

The model was used to extract the exchange current density of the anodic nitrite oxidation on nickel using experimental data. The data from a batch cell using an electrolyte having $879 \mathrm{ppm}$ chromate and no current reversal was chosen for extracting the nitrite oxidation kinetic parameters. In the presence of chromate and with no current reversal, the nitrate/nitrite reduction reactions can be assumed to be zero due to the passivation of the cathode surface. Therefore, the only path for a change in nitrate/nitrite oxidation is nitrite oxidation at the anode. The exchange current density of the nitrite oxidation was extracted using the model and the experimental values of nitrate/nitrite

\footnotetext{
Aspen Technology's dynamic flowsheet simulator software
} 
concentration and the comparison between the model predictions and experiment is shown in Figure 17.

The model was then used to predict concentrations of nitrate and nitrite in the absence of chromate. The kinetic parameters extracted by Don Wingard ${ }^{3}$ were used initially. However, to improve the agreement between the model predictions and experimental results, the value of the exchange current density for nitrate to nitrite reduction had to be increased an order of magnitude. The model and experimental comparisons are shown by dashed lines and open symbols in Figure 18. The next step was to use the model to predict the experimental results obtained from a flow cell run with chromate and current reversal. The presence of chromate and current reversal would lead to exchange current densities for the cathodic reactions which are constant with time but at a magnitude less that those in absence of chromate. It was assumed that the effect of chromium film would be same on the exchange current densities of all the cathodic reactions except hydrogen evolution. Hydrogen evolution would be unaffected as found earlier from the cyclic voltammograms on all the electrode materials tested including nickel. The model predictions agreed reasonably with the experimental results when the magnitude of the exchange current densities of nitrate and nitrite reactions were made 20 times less than their values in absence of chromate. The results are shown by solid lines and darkened symbols in Figure 18. The model predictions for nitrite concentration decrease more slowly than the experimental results for times greater than 10 hours. This may be due to non-uniform effects of chromium film on the exchange current densities of the four nitrate and nitrite cathodic reactions rather than a uniform effect assumed in the model. Additional experimental studies should be done in the future to investigate the effect on the chromium film on each exchange current density and incorporate them in the model to improve the model predictions. The model parameters and exchange current densities extracted in this work are summarized in Table 2. 
Task 5: Electrochemical Reduction of Nitrates and Nitrites in Alkaline Media in the Presence of Hexavalent Chromate.

\section{Introduction}

Previous studies have shown that feeding a waste simulant containing nitrate, nitrite and caustic to a parallel-plate electrochemical reactor, effectively reduces it to ammonia, nitrogen and hydrogen at the nickel cathode according to the following reactions $\mathrm{s}^{1,12-13}$ $(\mathrm{SHE}=$ Standard hydrogen electrode):

$$
\begin{array}{cc}
\mathrm{NO}_{3}^{-}+\mathrm{H}_{2} \mathrm{O}_{(\mathrm{l})}+2 \mathrm{e}^{-} \Leftrightarrow \mathrm{NO}_{2}^{-}+2 \mathrm{OH}^{-} & 0.01 \\
\mathrm{NO}_{2}^{-}+5 \mathrm{H}_{2} \mathrm{O}_{(1)}+6 \mathrm{e}^{-} \Leftrightarrow \mathrm{NH}_{3(\mathrm{~g})}+7 \mathrm{OH}^{-} & -0.165 \\
2 \mathrm{NO}_{2}^{-}+4 \mathrm{H}_{2} \mathrm{O}_{(1)}+6 \mathrm{e}^{-} \Leftrightarrow \mathrm{N}_{2(\mathrm{~g})}+8 \mathrm{OH}^{-} & 0.406 \\
2 \mathrm{H}_{2} \mathrm{O}_{(1)}+2 e^{-} \Leftrightarrow \mathrm{H}_{2(\mathrm{~g})}+2 \mathrm{OH}^{-} & -0.828
\end{array}
$$

The oxidation of nitrate to nitrite via reaction [1] can occur at the anode along with the evolution of oxygen:

$$
\begin{array}{cc}
4 \mathrm{OH}^{-} \Leftrightarrow \mathrm{O}_{2(\mathrm{~g})}+2 \mathrm{H}_{2} \mathrm{O}_{(1)}+4 \mathrm{e}^{-} & \left.\mathrm{U}^{9} \mathrm{~V} \text { vs. SHE }\right) \\
& 0.401
\end{array}
$$

Unfortunately, the presence of hexavalent chromium effectively stops reaction [1] at the cathode ${ }^{4,14}$. Adding bismuth salts to the electrolyte improves the current efficiency of reaction [1] but the effect is temporary since the bismuth eventually deposits on the anode $^{12}$. Lead electrodes have been proposed by Bockris and $\mathrm{Kim}^{15}$ as capable of reducing the nitrates and nitrites in the presence of chromate. However, environmental considerations as well as lead corrosion renders this alternative undesirable. Removing the chromate prior to the electrochemical reactor is a possible solution, but the relatively low 
concentration of $\mathrm{Na}_{2} \mathrm{CrO}_{4}$ among numerous other waste constituents suggests that a removal step would be very costly.

The objective of this task was to develop a procedure by which nitrates and nitrites can be reduced electrochemically in the presence of chromate. Specifically, we examined the procedure of reversing the polarity of the electrodes at constant time intervals in order to minimize the adverse effect of chromate. Since nickel serves as both the anode and cathode, we hypothesize that the passivating trivalent chromium oxide film that is believed to interfere with the desired reduction process ${ }^{15}$ can be reoxidized to the soluble hexavalent form by periodic reversion of the electrodes polarity.

\section{Experimental}

All experiments were performed in the undivided cell shown in Figure 2. The cell contained $100 \mathrm{ml}$ of electrolyte which contained $1.95 \mathrm{M} \mathrm{NaNO}_{3}, 0.6 \mathrm{M} \mathrm{NaNO}_{2}, 1.33 \mathrm{M}$ $\mathrm{NaOH}$ and varying concentrations of $\mathrm{Na}_{2} \mathrm{CrO}_{4}$. The anode and cathode were $99.9 \%$ nickel with a front face area of $16 \mathrm{~cm}^{2}$. The backsides of the electrodes were assumed inactive. Unless otherwise noted, the nickel electrodes were polished with 800-grit sandpaper, rinsed with $0.05 \mathrm{M} \mathrm{HCl}$ and washed with distilled water previous to placing them in the cell. An electrode prepared by this procedure will be referred as a new electrode. Constant current was provided by a Bitrode Multicell Charger, and electric timers together with double-pole double-throw switches were used to reverse the electrode polarity at constant intervals. One-milliliter samples were withdrawn throughout a run, and the nitrate and nitrite concentration was measured using an ion chromatograph (DIONEX 500IC). The temperature of the solution was recorded as a function of time. The temperature rises to a steady state value in approximately 30 minutes; this final temperature is reported as the average temperature. The water loses due to evaporation was replenished by periodic addition of de-ionized water in order to maintain a fixed electrolyte level in the cell. 


\section{Results and Discussion}

The effect of chromate on the electrochemical destruction of nitrites and nitrates is shown in Figure 19. When a constant current of 2.5A is applied in the absence of $\mathrm{Na}_{2} \mathrm{CrO}_{4}$, the nitrate concentration decreases slowly for the first five hours. This relatively slow concentration decrease is due to production of nitrate at the anode offsetting the destruction at the cathode. As the nitrite concentration decreases, the rate of nitrate destruction increases. Adding $35 \mathrm{ppm}$ and $879 \mathrm{ppm}$ of $\mathrm{Na}_{2} \mathrm{CrO}_{4}$ to the electrolyte does not affect the oxidation of nitrites to nitrates, but it effectively stops the nitrate reduction reaction. At 879 ppm of $\mathrm{Na}_{2} \mathrm{CrO}_{4}$, the nitrate concentration actually increases from 1.95 $\mathrm{M}$ to about 2.3 $\mathrm{M}$ due to the oxidation of nitrites to nitrates coupled with negligible nitrate destruction. The passivating effect of hexavalent chromate is most likely due to reduction of $\mathrm{CrO}_{4}^{-2}$ to trivalent chromium oxide at the cathode according to the following reaction ${ }^{15-}$ 19

$$
\mathrm{U}^{\theta} \text { (V vs. SHE) }
$$

$$
\mathrm{CrO}_{4}^{-2}+4 \mathrm{H}_{2} \mathrm{O}+3 \mathrm{e}^{-} \Leftrightarrow \mathrm{Cr}(\mathrm{OH})_{3}+5 \mathrm{OH}^{-} \quad-0.11 \mathrm{~V}
$$

Since the $\mathrm{Cr}(\mathrm{OH})_{3}$ species is insoluble in caustic solution ${ }^{17}$, the solid deposits on the cathode and virtually stops reaction $[1]^{15,16}$. The oxidation via reaction $[1]$, however, can still occur at the anode, thus causing a decrease in the nitrite concentration regardless of the amount of $\mathrm{Na}_{2} \mathrm{CrO}_{4}$ present in the electrolyte. Even a $\mathrm{Na}_{2} \mathrm{CrO}_{4}$ concentration as small as $35 \mathrm{ppm}$, the $\mathrm{Cr}(\mathrm{OH})_{3}$ film is capable of inhibiting reaction [1] at the cathode as shown in Figure 19.

In order to understand the redox reaction of hexavalent chromate at a nickel electrode, cycle voltammograms (CV) in $1.33 \mathrm{M} \mathrm{NaOH}$ with and without chromate are shown in Figure 20. The large currents at -1.3 and $0.9 \mathrm{~V}$ correspond to hydrogen and oxygen evolution, respectively, and the peaks on nickel between 0.3 and $0.45 \mathrm{~V}$ correspond to the nickel hydroxide redox reaction. Figure 20 also shows a $\mathrm{CV}$ at a gold 
electrode with $5000 \mathrm{ppm}$ of $\mathrm{Na}_{2} \mathrm{CrO}_{4}$ dissolved in $1.33 \mathrm{M} \mathrm{NaOH}$. The peak at $-0.7 \mathrm{~V}$ is attributed to the reduction of chromate to $\mathrm{Cr}$ (III) via reaction $[6]^{17-19}$. There is a sharp decrease in the cathodic current at potentials below $-0.7 \mathrm{~V}$. The decrease in the current is due to the passivating effect of the $\mathrm{Cr}$ (III) which forms a solid layer of trivalent chromium hydroxide on the electrode surface ${ }^{17-19}$ Surprisingly, no such peaks is present on the nickel electrode between -1.1 and $-0.4 \mathrm{~V}$, and yet Figure 19 clearly indicates an inhibiting effect of the hexavalent chromate. This seems to indicate that the trivalent chromium film formed on the nickel surface is either very thin and/or that it grows slowly on the surface of the electrode.

The conclusion from the results in Figure 19 is that it is not possible to reduce nitrates and nitrites in the presence of $\mathrm{Na}_{2} \mathrm{CrO}_{4}$ by applying a constant current. However, when the electrodes polarity is reversed every 30 minutes, Figure 21 shows that the nitrate/nitrite destruction may proceed at an acceptable rate. Several $\mathrm{Na}_{2} \mathrm{CrO}_{4}$ concentrations were tested ranging from 8.8 to $15000 \mathrm{ppm}$, and three of such runs are shown in Figure 21. The SRS waste stream contains an average concentration of 880 ppm of $\mathrm{Na}_{2} \mathrm{CrO}_{4}(0.033 \mathrm{M})$.

All the results performed at constant current and when the current polarity is reversed every 30 minutes are summarized in Figure 22 by plotting the nitrate concentration after 24 hours of operation versus the hexavalent chromium concentration. In all three runs the initial $\mathrm{NaNO}_{3}$ and $\mathrm{NaNO}_{2}$ concentrations are $1.95 \mathrm{M}$ and $0.6 \mathrm{M}$, respectively and the final nitrite concentration is practically zero. If $\mathrm{Na}_{2} \mathrm{CrO}_{4}$ is not present, Figure 22 shows that the nitrate concentration after 24 hours is approximately $0.25 \mathrm{M}$ which corresponds to a $90 \%$ destruction of nitrate and nitrite. At a $\mathrm{Na}_{2} \mathrm{CrO}_{4}$ concentration of $8.8 \mathrm{ppm}$, the nitrate concentration is approximately $1.8 \mathrm{M}(29 \%$ destruction of nitrite and nitrate), and at $\mathrm{Na}_{2} \mathrm{CrO}_{4}$ concentrations over $500 \mathrm{ppm}$, the nitrate concentration is approximately $2.35 \mathrm{M}(7.8 \%$ nitrate and nitrite destruction). When the electrode polarity is reversed, $\mathrm{Na}_{2} \mathrm{CrO}_{4}$ also decreases the efficiency of the process up 1000 ppm. At $\mathrm{Na}_{2} \mathrm{CrO}_{4}$ concentrations over $1000 \mathrm{ppm}$, the nitrate concentration after 24 hour of reaction time is approximately 0.7 which corresponds to a $73 \%$ destruction of nitrate and nitrite. Further increases on chromate concentration have no effect on the 
efficiency of the process. Figure 22 emphasizes the fact that even small amounts of chromate affect the nitrate and nitrite reduction process.

Different reversal time intervals were studied in order to maximize the rate of the reduction of the nitrates and nitrites. Figure 23 presents the effect of different reversal times on a test solution containing $7000 \mathrm{ppm}$ of $\mathrm{Na}_{2} \mathrm{Cr}_{2} \mathrm{O}_{7}$. The results for the cases with no chromium present and no reversal of the electrodes polarity are presented for comparison purposes. The nitrite concentrations are not shown since they are roughly the same as those presented in Figure 21. The runs with a reversal time of 1 and 2 hours result in a faster destruction of nitrate than did the runs with either larger or smaller reversal times. This indicates that there is an optimum reversal time for the operation of the undivided cell. At very large times, the electrode spends most of the time poisoned by the chromate film and logically the efficiencies are low. It was surprising, however, that at small reversal times the efficiency was also low. It is believed that the trivalent chromium oxide film forms slowly on the surface of the electrode and that it dissolves at an even slower rate. Therefore, very short reversal times will result in a cathode surface that retains a large fraction of the passive film.

Figure 24 shows the $\mathrm{NaNO}_{3}$ concentration after 24 hours of cell operation as a function of charge passed per cycle. Two different current densities were tested in a solution containing $880 \mathrm{ppm}$ of hexavalent chromium. The curve at $156.25 \mathrm{~mA} / \mathrm{cm}^{2}$ and $43{ }^{\circ} \mathrm{C}$ is a summary of the results presented in Figure 22 . A similar summary is presented for runs at $312.5 \mathrm{~mA} / \mathrm{cm}^{2}$ and $73{ }^{\circ} \mathrm{C}$. It can be seen that the optimum occurs at approximately the same amount of charge per half cycle. The optimum time per half cycle is near 1 hour at $156.25 \mathrm{~mA} / \mathrm{cm}^{2}$ and 30 minutes for $312.5 \mathrm{~mA} / \mathrm{cm}^{2}$. This corresponds to $10,000 \mathrm{C}$ per half cycle (i.e., $625 \mathrm{C} / \mathrm{cm}^{2}$ ). The temperature in the two runs described above was not controlled. Therefore, the higher current resulted in a higher steady-state temperature due to ohmic heating. To ensure that the optimum reversal time is due to a change in current rather than a change in temperature, the run at $312.5 \mathrm{~mA} / \mathrm{cm}^{2}$ was repeated with the cell in a cooling bath. The steady-state temperature for this run was 62 ${ }^{\circ} \mathrm{C}$. As expected, a lower efficiency is observed at the lower temperature, but the optimum reversal time still corresponds to the same charge density per half cycle. 
Long-term performance of the nickel electrode was studied to determine the longterm poisoning effect on the nickel electrodes. Figure 25 compares the performance of a set of new electrodes to electrodes after 300 and 500 hours of operation. Also shown are the results from electrodes after 750 hours of operation after rinsing with $0.05 \mathrm{M}$ oxalic acid. There is a small long-term decrease in the efficiency of the electrodes over time. However, the efficiency does not seem to decrease any further after 300 hours of operation. In addition, the oxalic acid wash regenerates the electrode close to its initial state. The practical implication is that it is not necessary to disassemble the parallel-plate reactor in order to reactivate the electrodes.

Finally, experiments were performed in the parallel-plate reactor to compare the efficiency of porous and planar electrodes. Figure 26 presents the results obtained when planar and porous electrodes were used with the polarity reversion technique. Porous electrodes, as expected, show higher efficiencies than planar electrodes. Figure 26 also shows that adding bismuth oxide to the electrolyte effectively increases the efficiency of the nickel electrodes.

\section{Conclusions}

The following conclusions resulted from this study:

- Hexavalent chromium concentration as low as $9 \mathrm{ppm}$ stops the electrochemical reduction of nitrates and nitrites when the cell is operated at constant current.

- The reduction process can proceed at acceptable rates in the presence of hexavalent chromate by reversing the polarity of the electrodes at constant time intervals.

- Optimal operating conditions occur when a charge density of $625 \mathrm{C} / \mathrm{cm}^{2}$ is passed on the nickel electrodes per half cycle.

- Any loss in efficiency over extended periods of operation ( $>300$ hours) can be recovered by washing the nickel electrodes with dilute oxalic acid $(0.05 \mathrm{M})$.

- In the parallel-plate reactor, porous electrodes show a higher efficiency than planar. This efficiency is increased even further by the addition of $0.5 \mathrm{~g} / \mathrm{L}$ of bismuth oxide. 


\section{Final Recommendations}

- Do not add a chromium removal stage prior to the denitration in the proposed Electrochemical Denitration and Caustic Recovery (EDCR) facility.

- Even in the presence of chromate, design the facility based on the preliminary conceptual design. The lone operational modification in the EDCR facility design is to allow for reversal of the current polarity at constant intervals. Based on laboratory testing, the optimum operational point for polarity reversal occurs at approximately $625 \mathrm{C} / \mathrm{cm}^{2}$ per half cycle.

- Porous electrodes and bismuth oxide may be used to increase the efficiency of the process. 


\begin{tabular}{|c|c|c|c|c|}
\hline $\begin{array}{l}\text { Electrode } \\
\text { material }\end{array}$ & physical form & $\begin{array}{l}\text { superficial } \\
\text { area }\left(\mathrm{cm}^{2}\right)\end{array}$ & $\begin{array}{c}\text { Electrode area per } \\
\text { volume }\left(\mathrm{a}, \mathrm{cm}^{-1}\right)\end{array}$ & $\begin{array}{l}\text { Sweep-rate } \\
\text { used in CV }\end{array}$ \\
\hline Gold & planar & 0.46 & - & 50 \\
\hline Nickel & planar & 1.80 & - & 100 \\
\hline Platinum & planar & 0.46 & - & 50 \\
\hline Glassy Carbon & planar & 0.26 & - & 50 \\
\hline Carbon Steel & planar & 1.80 & - & 50 \\
\hline Copper & planar & 1.90 & - & 50 \\
\hline Silver & planar & 0.01 & - & 50 \\
\hline Graphite & planar & 1.78 & - & 50 \\
\hline Vitreous Carbon & porous & 0.84 & 80 & 10 \\
\hline TySar SB ${ }^{\text {TM§ }}$ & porous & 1.33 & 60 & 10 \\
\hline TySar EP ${ }^{\mathrm{TM}^{* *}}$ & porous & 1.62 & 60 & 10 \\
\hline TySar IM ${ }^{\text {TMff }}$ & porous & 1.64 & 60 & 10 \\
\hline
\end{tabular}

Table1: Electrode materials evaluated using cyclic voltammetry technique

\footnotetext{
${ }^{5}$ High surface area titanium fiber porous electrode developed by Olin Corporation (Charleston Technology Center, Charleston, TN).

"* High surface area platinum loaded porous electrode developed by Olin Corporation.

${ }^{\dagger \dagger}$ High surface area proprietary intermetallic catalyst loaded porous electrode developed by Olin Corporation
} 


\begin{tabular}{|c|c|c|}
\hline Reaction \# & $\begin{array}{c}\text { Exchange-current Densities (in } \\
\text { absence of chromate) } \\
\left(\mathbf{A} / \mathbf{c m}^{2}\right)\end{array}$ & $\begin{array}{c}\text { Transfer coefficient } \\
\left(n \alpha_{c}\right)\end{array}$ \\
\hline $\begin{array}{l}1 \\
2 \\
3 \\
4 \\
5 \\
6 \\
7\end{array}$ & $\begin{array}{l}2.0 \times 10^{-9 *} \\
8.0 \times 10^{-7} \\
2.0 \times 10^{-11} \\
1.0 \times 10^{-11} \\
1.0 \times 10^{-06} \\
2.25 \times 10^{-4} \\
1.0 \times 10^{-11}\end{array}$ & $\begin{array}{r}0.40 \\
0.30 \\
0.30 \\
0.30 \\
0.64 \\
-\quad 0.81 \\
0.40\end{array}$ \\
\hline \multicolumn{3}{|c|}{ Physical parameters } \\
\hline $\begin{array}{l}\text { Electrode material } \\
\text { Current density }\left(\mathrm{A} / \mathrm{cm}^{2}\right) \\
\text { Electrolyte volume }\left(\mathrm{cm}^{3}\right) \\
\text { Electrolyte flow rate }\left(\mathrm{cm}^{3} / \mathrm{s}\right) \\
\text { Operation temperature }\left({ }^{\circ} \mathrm{C}\right) \\
\text { Superficial Electrode area }\left(\mathrm{cm}^{2}\right) \\
\text { Diffusion layer thickness }(\mathrm{cm}) \\
\text { Multiplier for exchange current } \\
\text { densities } 1-4 \text { to account for the } \\
\text { effect of chromate: }\end{array}$ & $\begin{array}{l}\text { Nickel foil } \\
0.25 \\
2000 \\
31.5 \\
37 \text { (approx.) } \\
100.0 \\
16.4 \times 10^{-3}\end{array}$ & \\
\hline
\end{tabular}

Table 2: Kinetic and Physical parameters for the model/experiment comparisons. * implies that this value is 10 times more than the one extracted by Don Wingard. 


\section{References}

1. D. T. Hobbs, "Electrochemical Treatment of Nuclear Waste at Savannah River Site" in Electrochemistry for a Cleaner Environment, J. D. Genders and N. L. Weinberg, Editors, The Electrosynthesis Company, Amherst, New York (1992).

2. K. Jha, J. Weidner, and R. E. White, "Progress Report on the Evaluation of a Porous Cathode Used for the Electrochemical Reduction of Nitrates and Nitrites in Liquid Wastes", WSRTC-TR-95-0438, September 26, 1995.

3. D. Wingard, "Parallel plate reactor model for the electrochemical treatment of liquid wastes", Ph.D. thesis (1995), University of South Carolina ,Columbia.

4. Hu-lin Li, D. Robertson, J. Chambers, and D. T. Hobbs, J. Electrochem. Soc., 135, 1154 (1988).

5. J. Kim and J. O'M. Bockris, “ Packed and Fluidized-bed electrodes”, June 301995 (WSRC-TR-95-0310).

6. J. D. Genders, N. Weinberg, and D. Hartsough, "Phase II Final ReportElectrochemical Processing of Nitrate Waste Solutions, (U)" October 7, 1992 (WSRCTR-93-090).

7. D. Lindbergh and D. Simonsson, Electrochemica Acta, 36, 1985 (1991).

8. D. Sazou and G. Kokkinidis, J. Electroanal. Chem., 271, 221 (1989).

9. C. C. Streinz, S. Motupally, and J. W. Weidner, J. Electrochem. Soc., 142, 4051 (1995).

10. C. C. Streinz, A. P. Hartman, S. Motupally, and J. W. Weidner, J. Electrochem. Soc., 143, 2319 (1996).

11. S. Prasad, J. W. Weidner and A. E. Farell, J. Electrochem. Soc., 142, 3815 (1995).

12. D. T. Hobbs and M Ebra, AIChE Symp. Series No. 254, 83, 149 (1987)

13. D. H. Coleman and R. E. White, J. Electrochem. Soc., 142, 1152 (1995)

14. J. D. Genders, D. Hartsough and D. T. Hobbs, J. of Appl. Electrochem., 26, 1 (1996) 
15. J. O'M. Bockris and J. Kim, J. of Appl. Electrochem., 27, 623 (1997)

16. D. Sazou and G. Kokkinidis, J. Electroanal. Chem., 271, 221 (1989)

17. G. Lindenbergh and D. Simonsson, Electrochimica Acta, 36, 1985 (1991)

18. A. Cornell, G. Lindbergh and D. Simonsson, , Electrochimica Acta, 37, 1973 (1992)

19. G. Lindbergh and D. Simonsson, J. Electrochem. Soc., 137, 3094 (1990) 


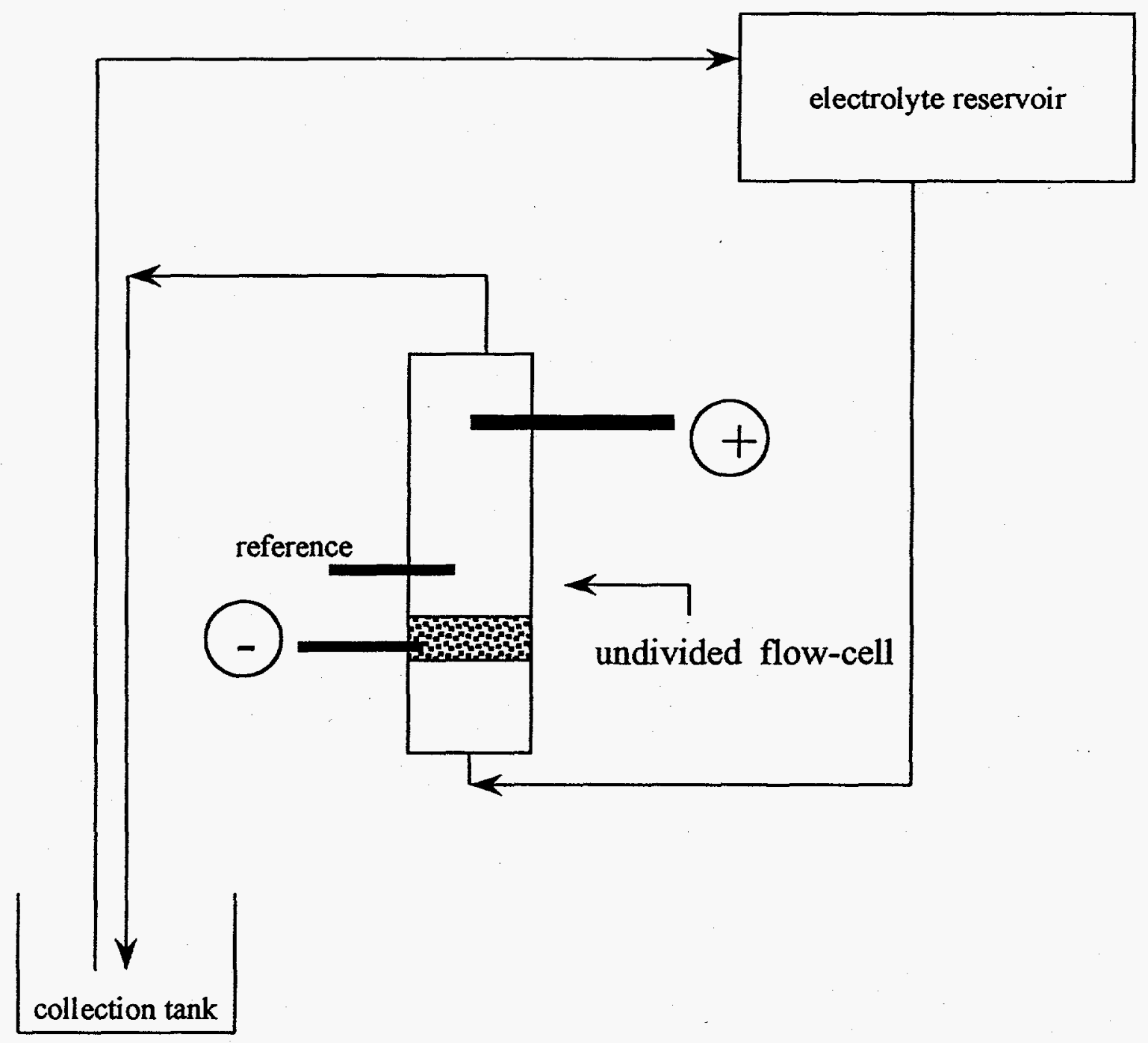

Figure 1: Schematic of the undivided drip flow-cell. Nickel foam is used as the cathode, graphite rod as the anode and $\mathrm{Ag} / \mathrm{AgCl}$ as the reference electrode. 


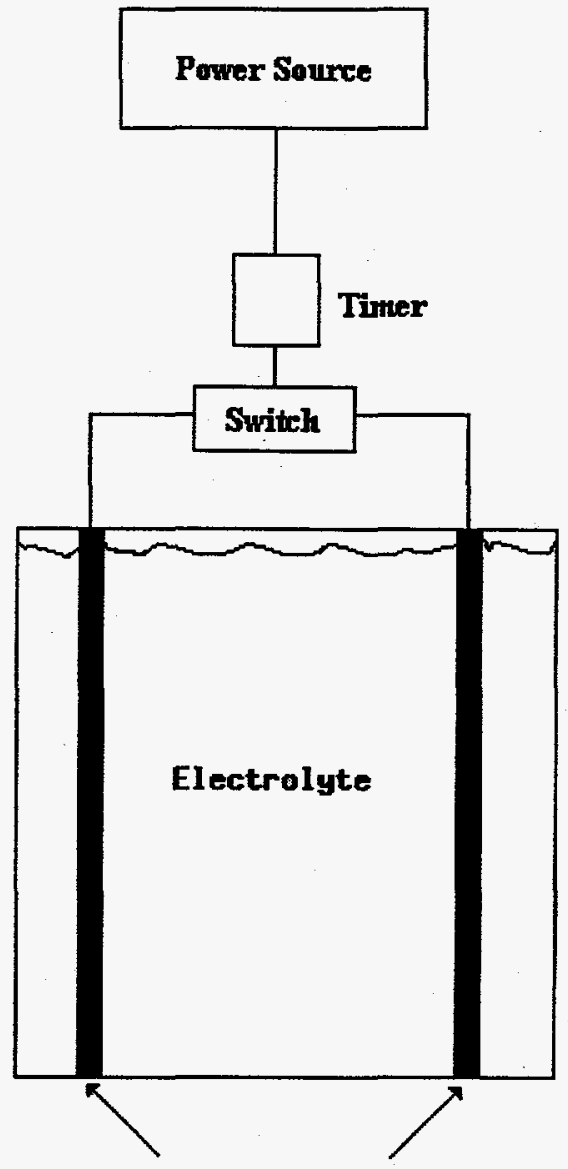

Nickel Electrodes

Fig. 2. A schematic of an undivided electrochemical cell. The anode and cathode were $99.9 \%$ nickel with a front area of $16 \mathrm{~cm}^{2}$. The back side of the electrode were assumed inactive. The cell contained a volume of $100 \mathrm{~cm}^{3}$ of the simulant waste. 


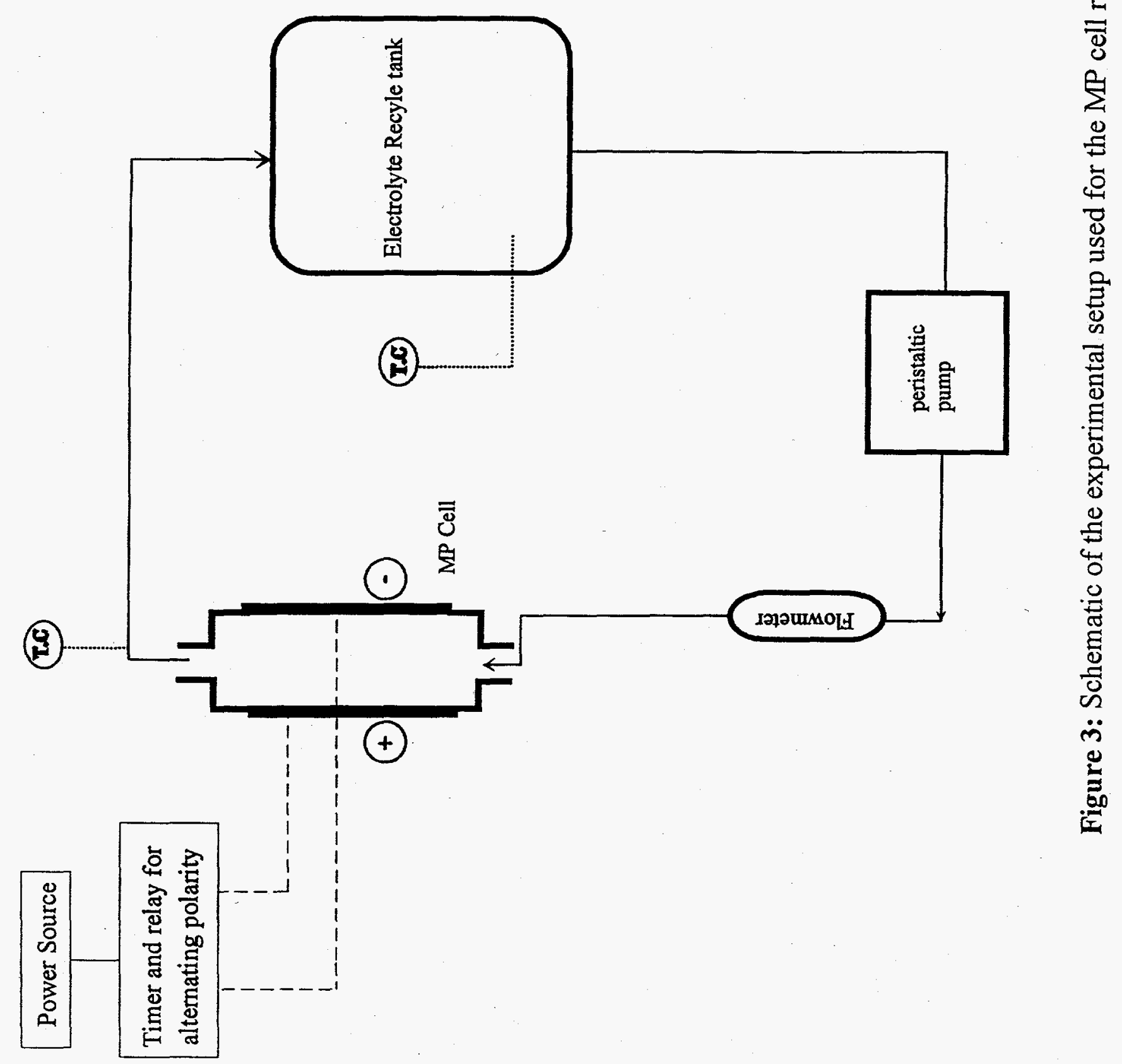



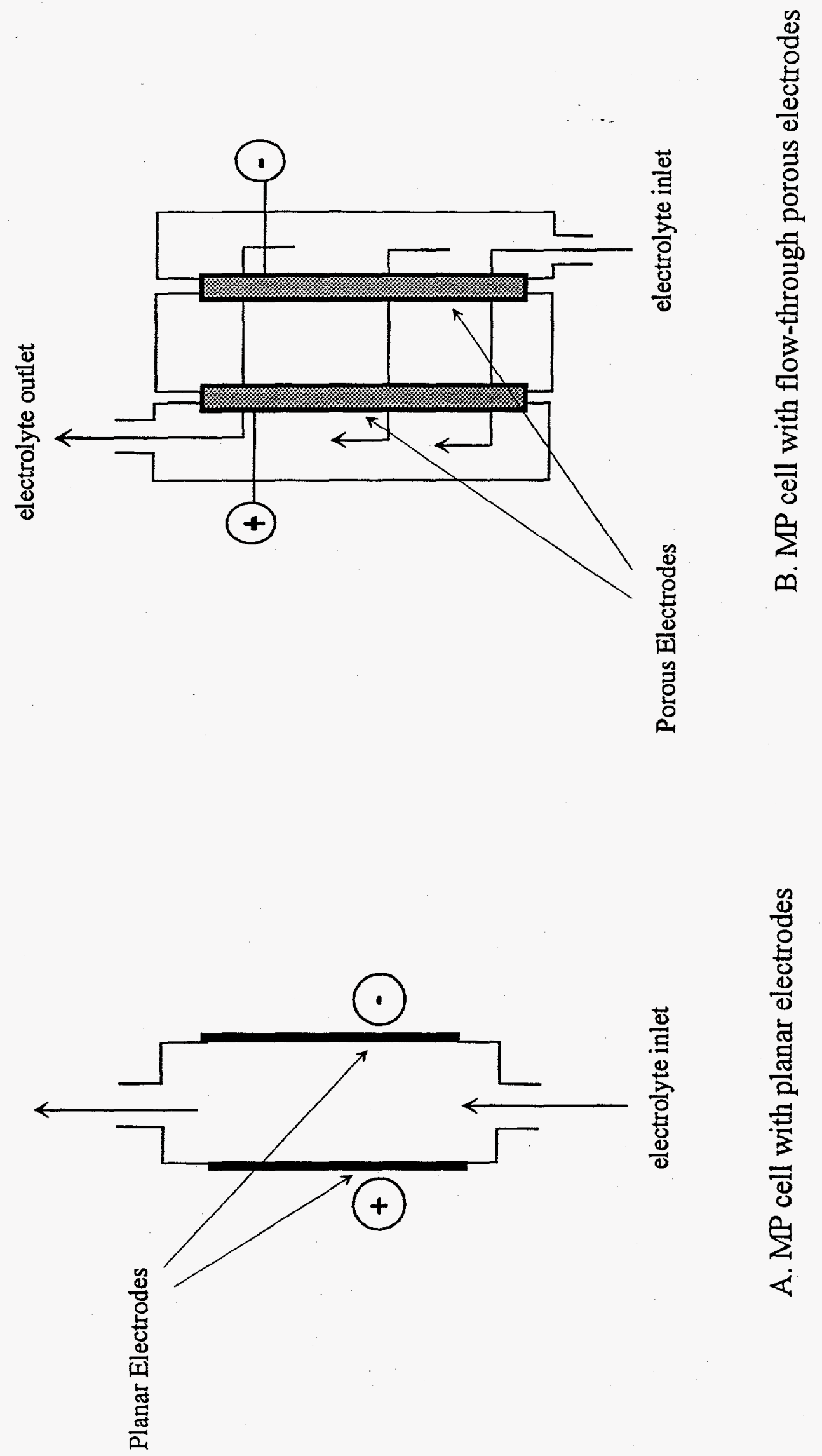


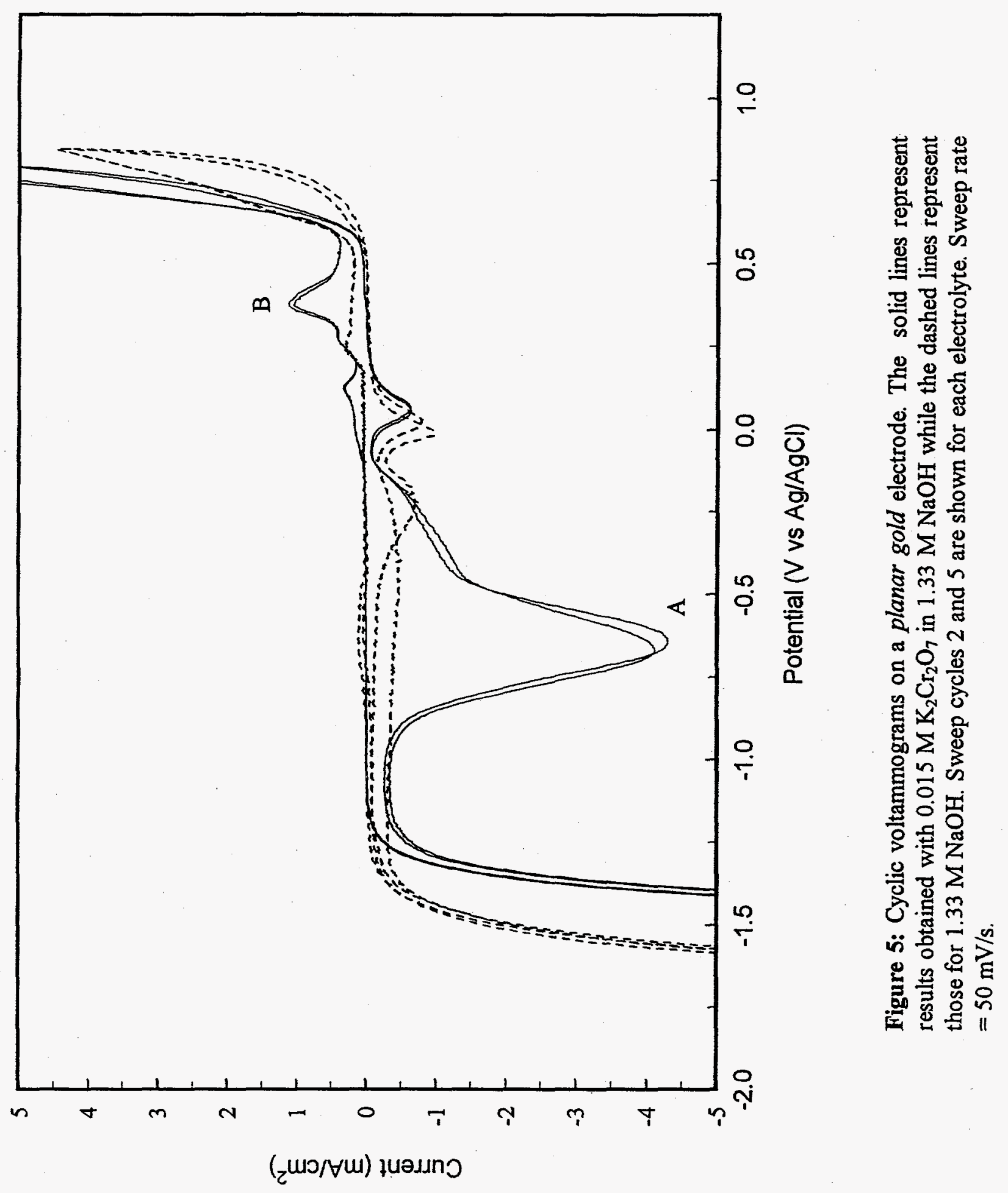




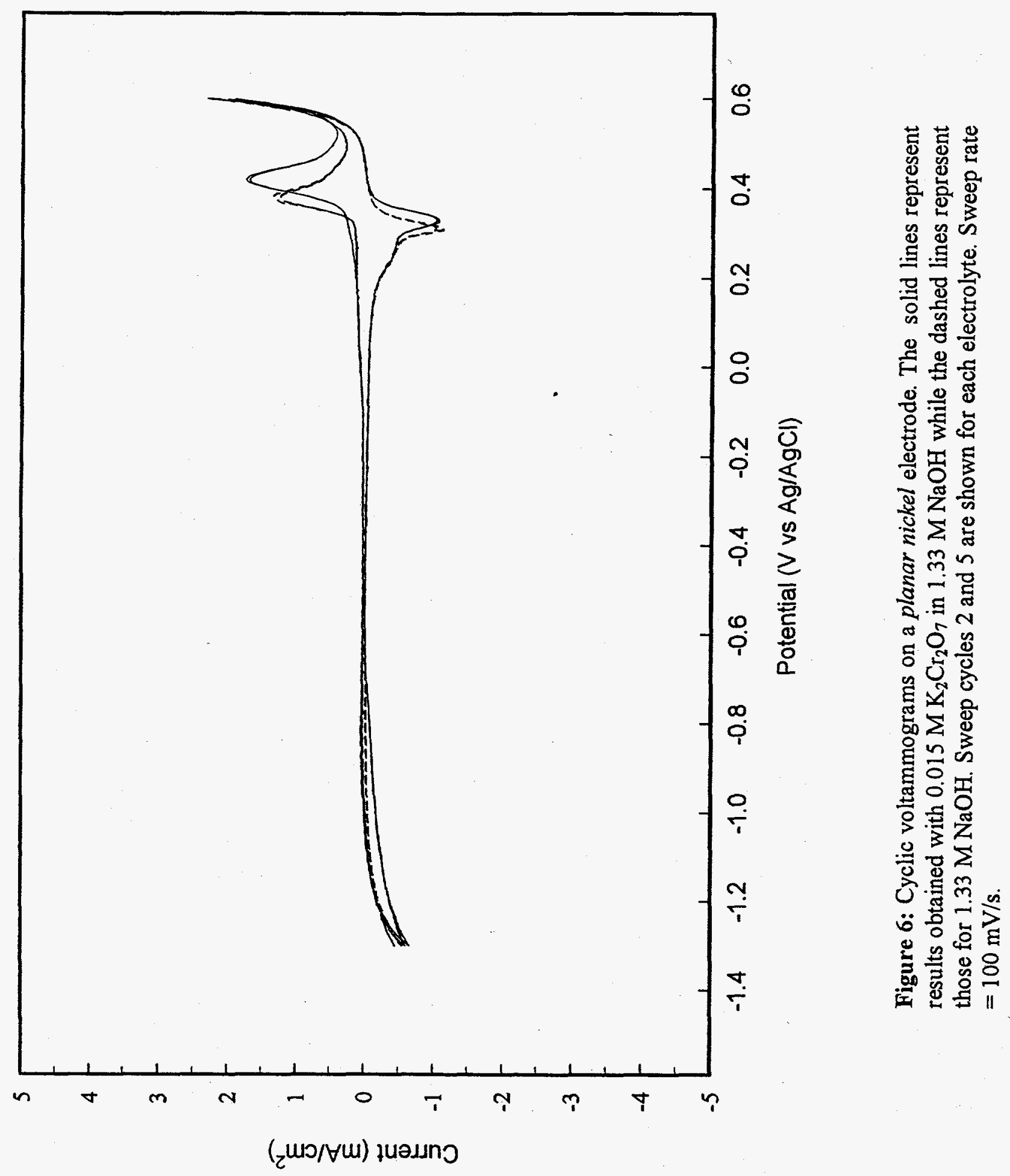




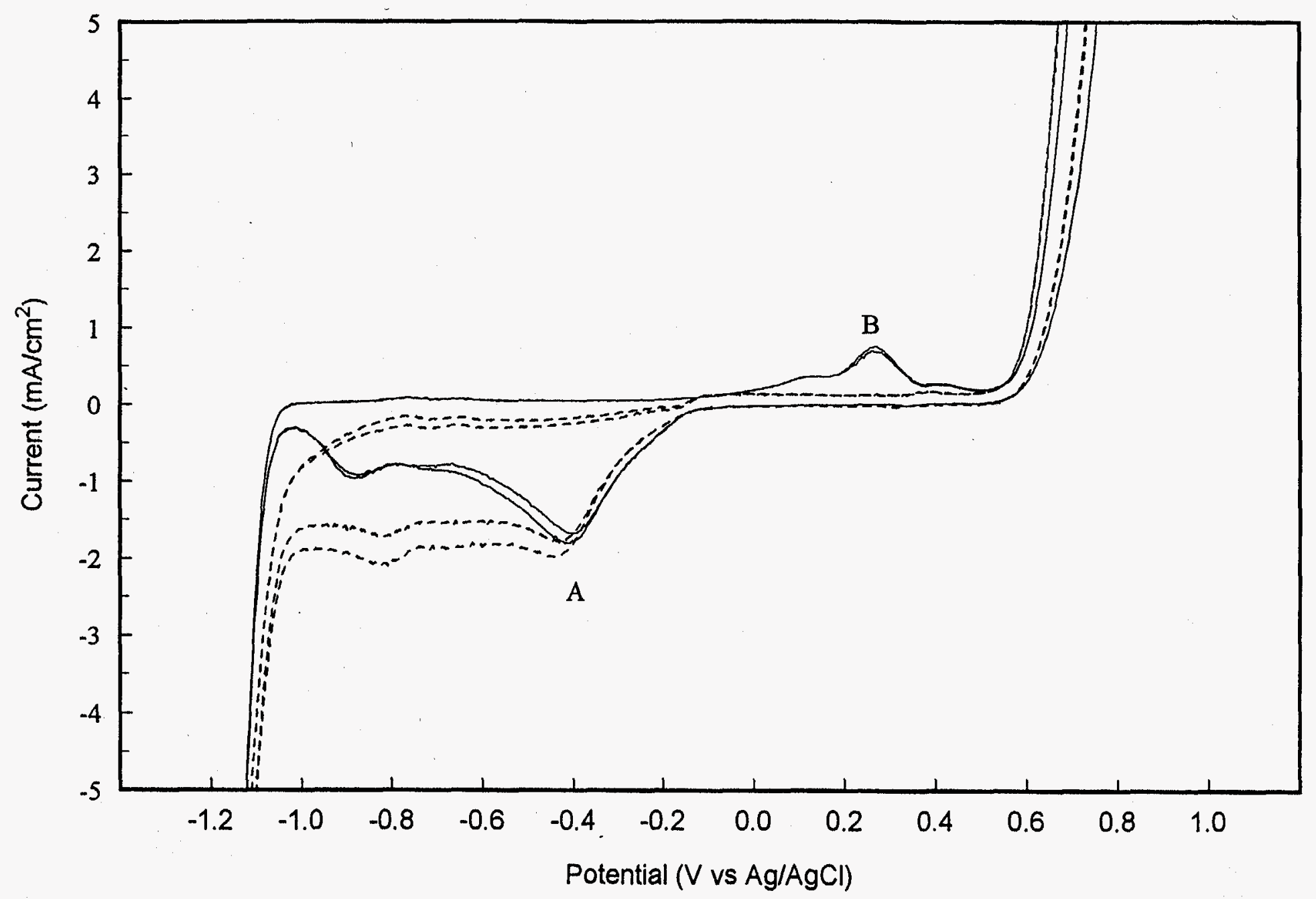

Figure 7: Cyclic voltammograms on a planar platinum electrode. The solid lines represent results obtained with $0.015 \mathrm{M} \mathrm{K}_{2} \mathrm{Cr}_{2} \mathrm{O}_{7}$ in $1.33 \mathrm{M} \mathrm{NaOH}$ while the dashed line represent those for $1.33 \mathrm{M} \mathrm{NaOH}$. Sweep cycles 2 and 5 are shown for each electrolyte. Sweep rate $=50 \mathrm{mV} / \mathrm{s}$. 


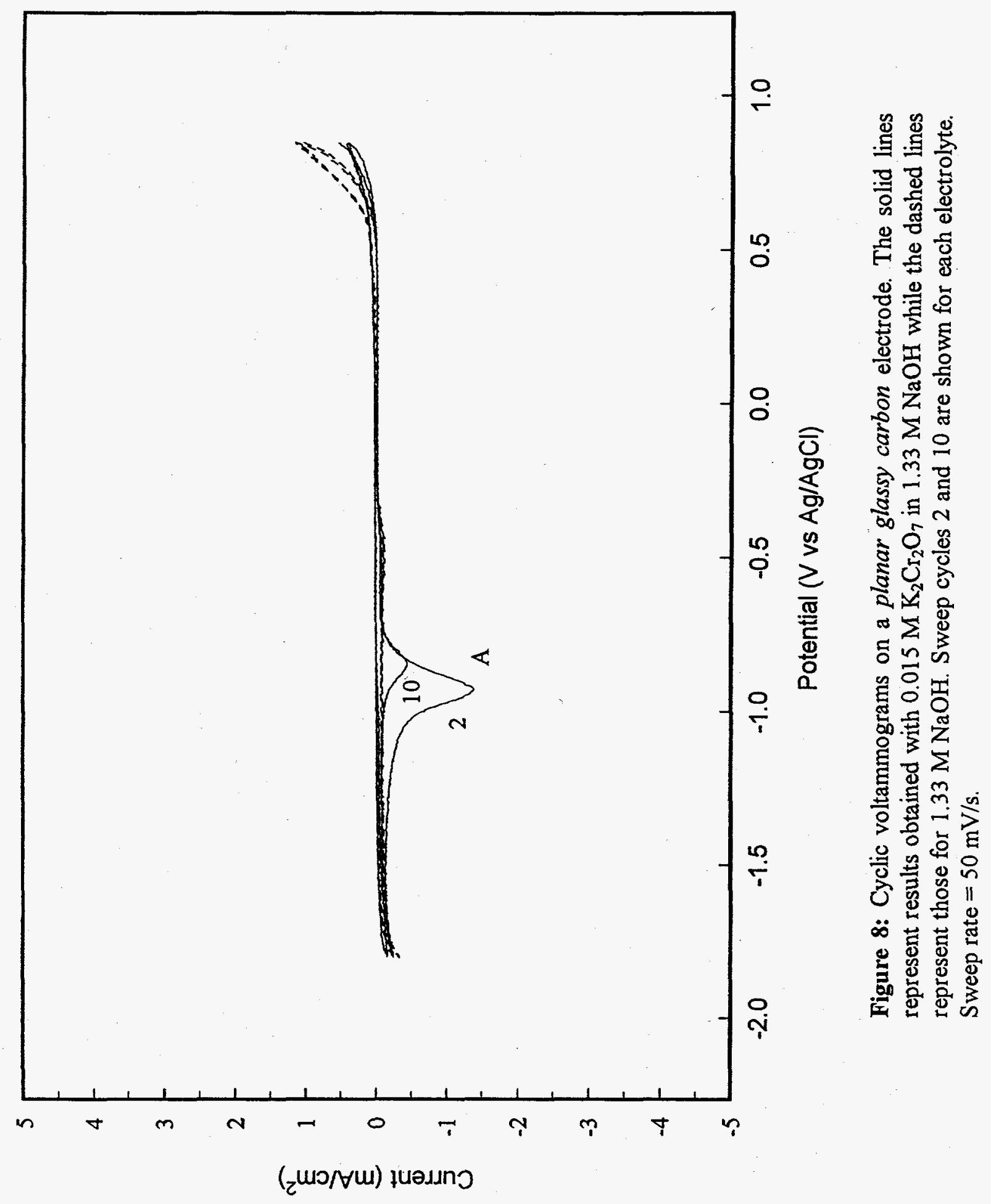




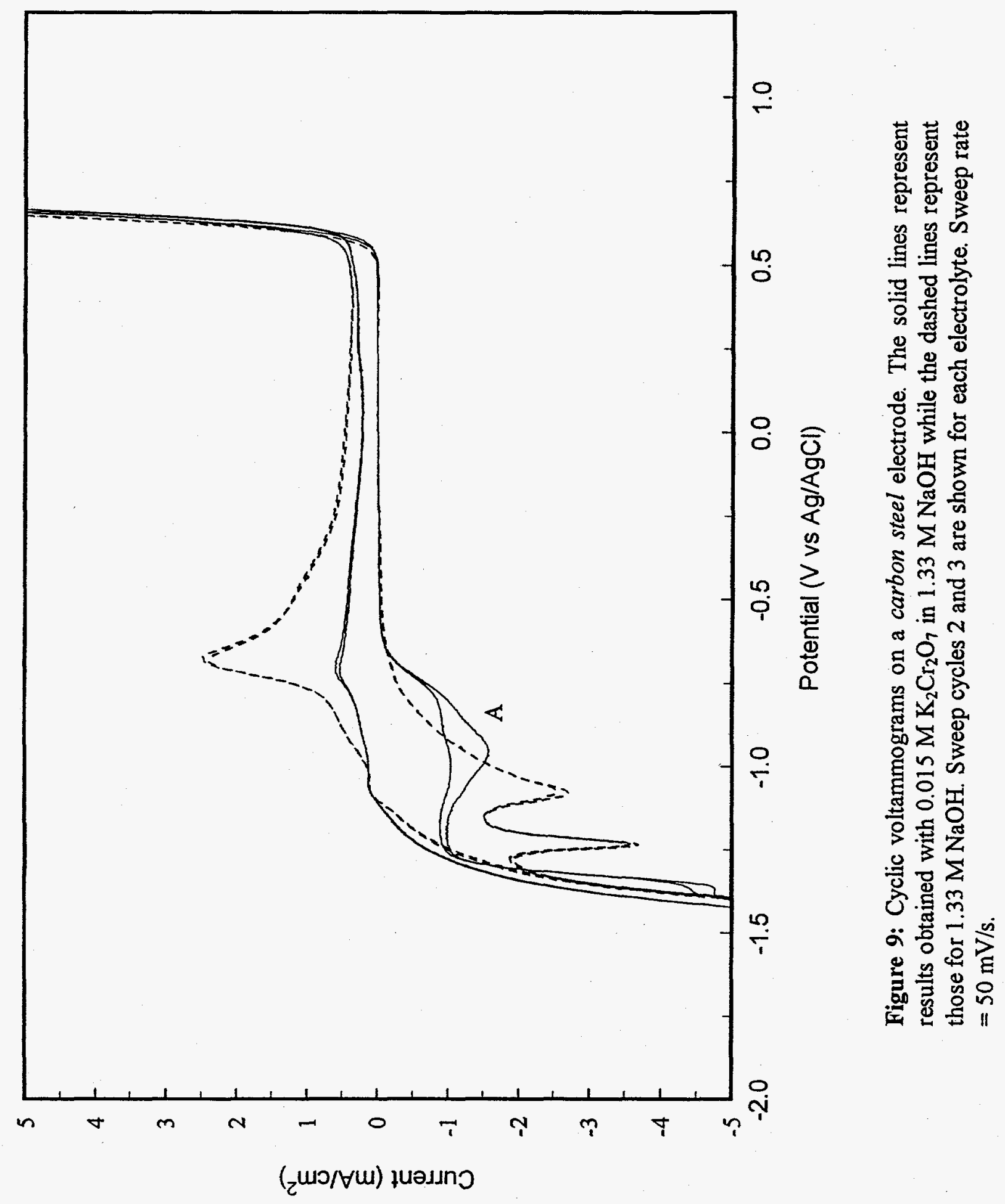




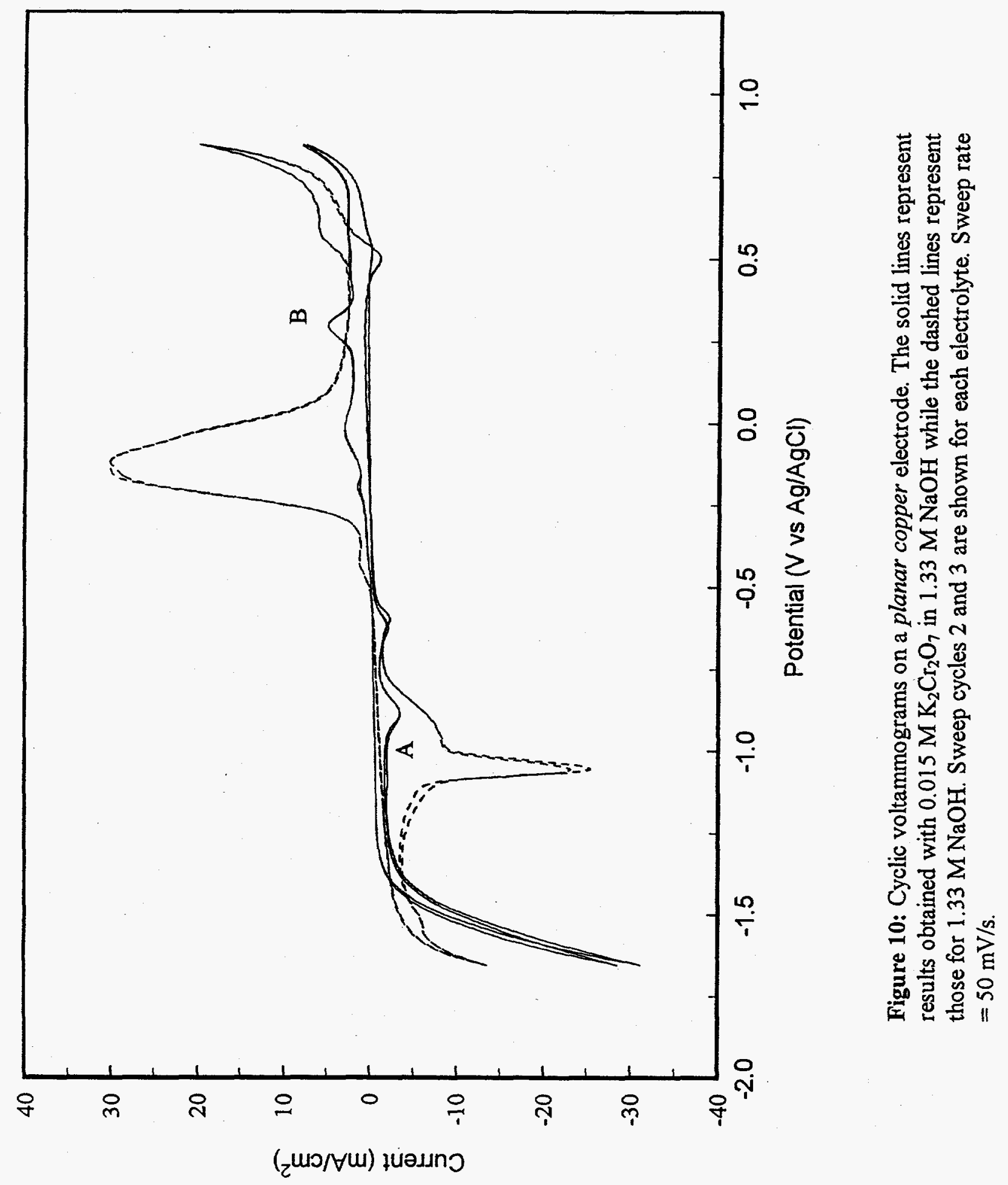




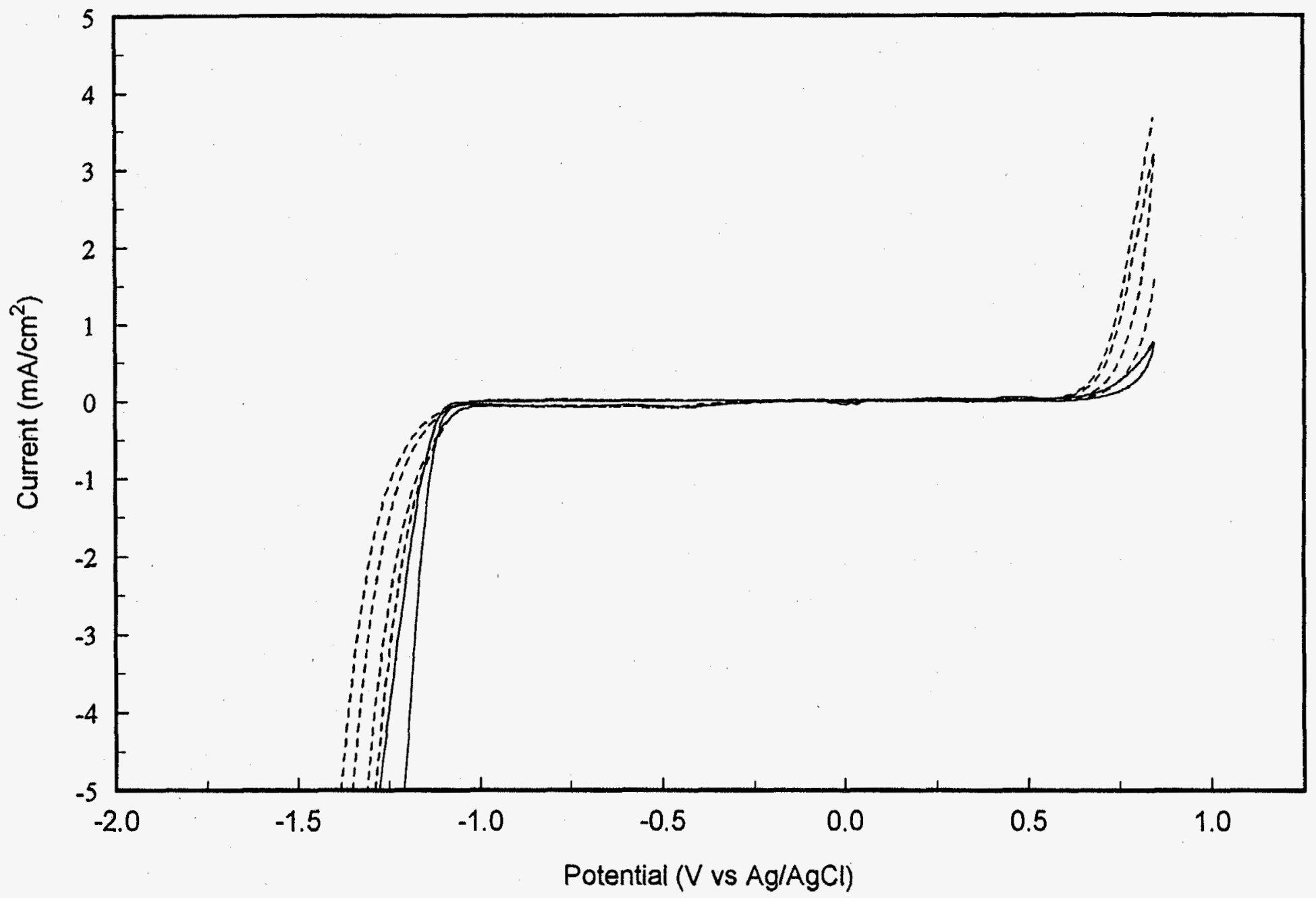

Figure 11: Cyclic voltammograms on a silver wire electrode. The solid lines represent results obtained with $0.015 \mathrm{M} \mathrm{K}_{2} \mathrm{Cr}_{2} \mathrm{O}_{7}$ in $1.33 \mathrm{M} \mathrm{NaOH}$ while the dashed lines represent those for $1.33 \mathrm{M} \mathrm{NaOH}$. Sweep cycles 2 and 3 are shown for each electrolyte. Sweep rate $=50 \mathrm{mV} / \mathrm{s}$. 


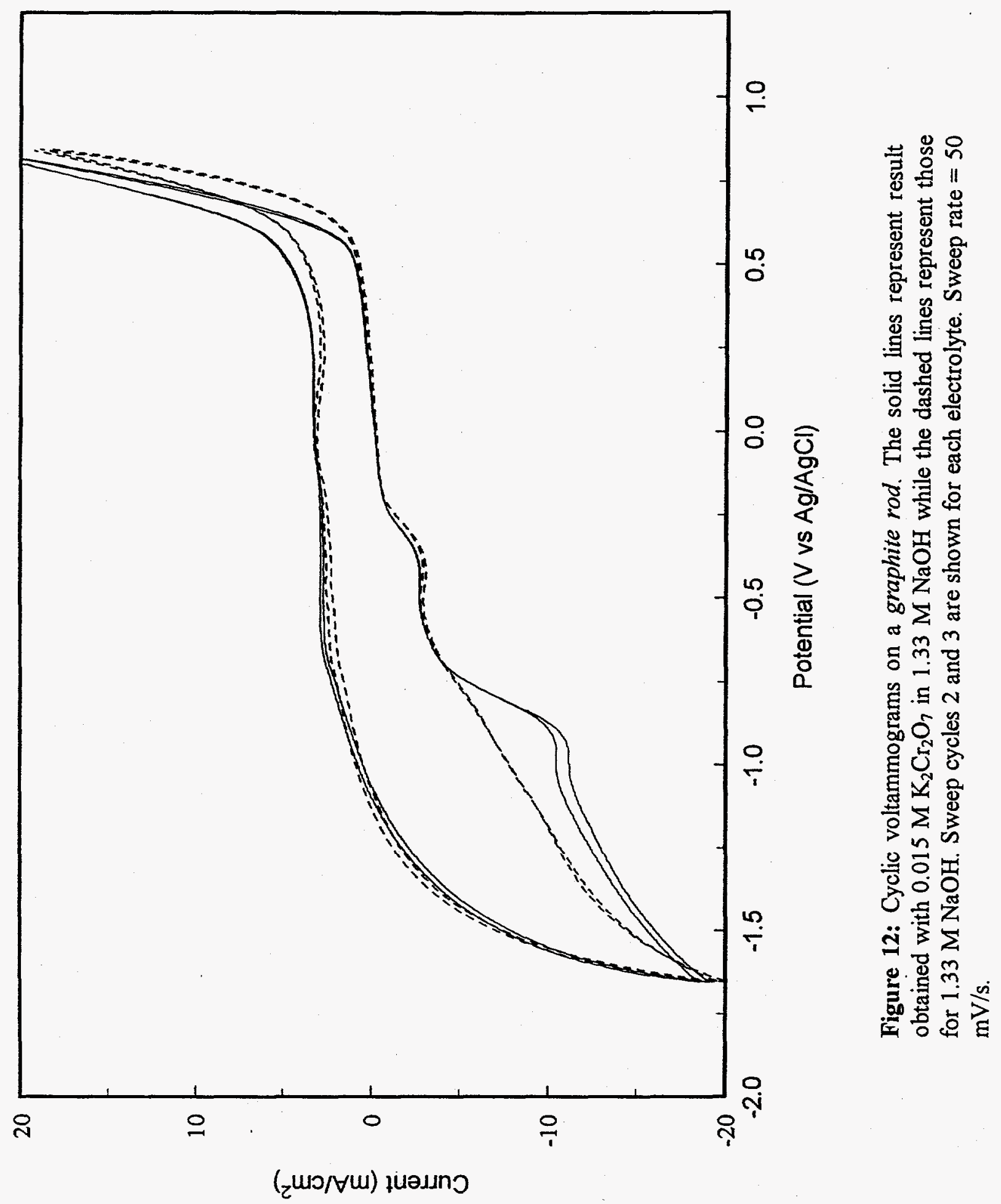




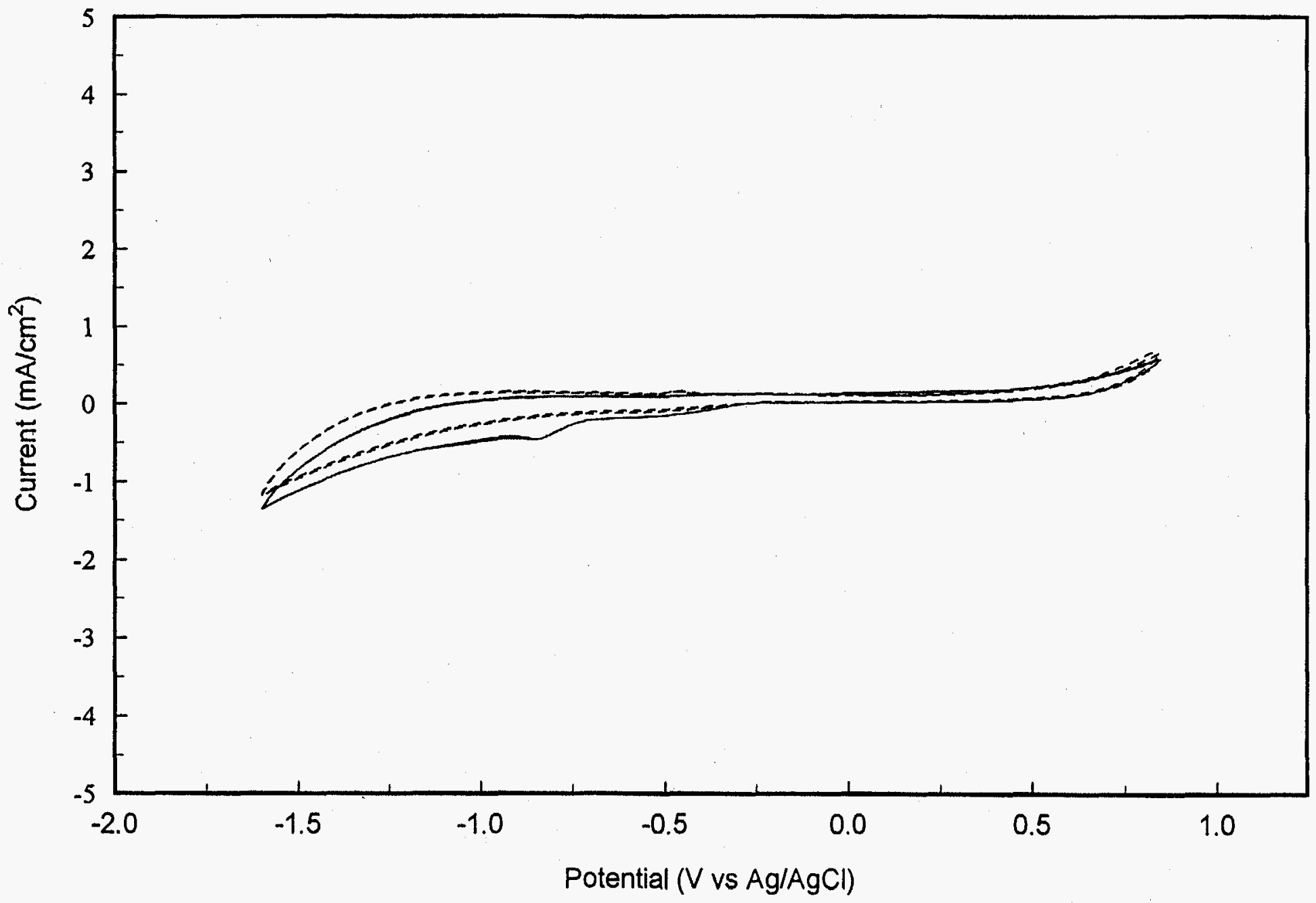

Figure 13: Cyclic voltammograms on a porous vitreous carbon electrode. The solid lines represent results obtained with $0.015 \mathrm{M} \mathrm{K}_{2} \mathrm{Cr}_{2} \mathrm{O}_{7}$ in $1.33 \mathrm{M} \mathrm{NaOH}$ while the dashed line represent those for $1.33 \mathrm{M} \mathrm{NaOH}$. Sweep cycles 2 and 3 are shown for each electrolyte. Sweep rate $=10 \mathrm{mV} / \mathrm{s}$. 


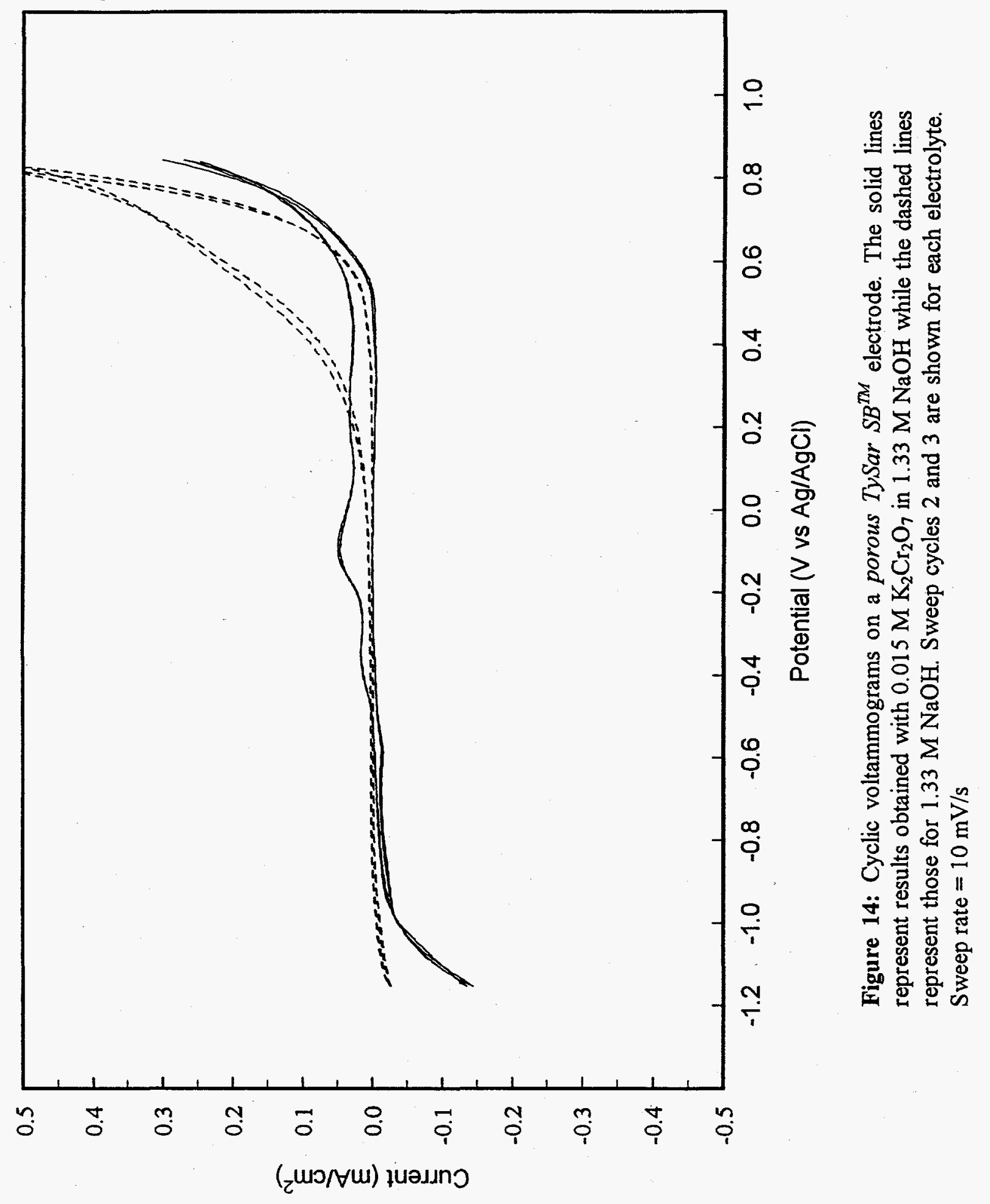




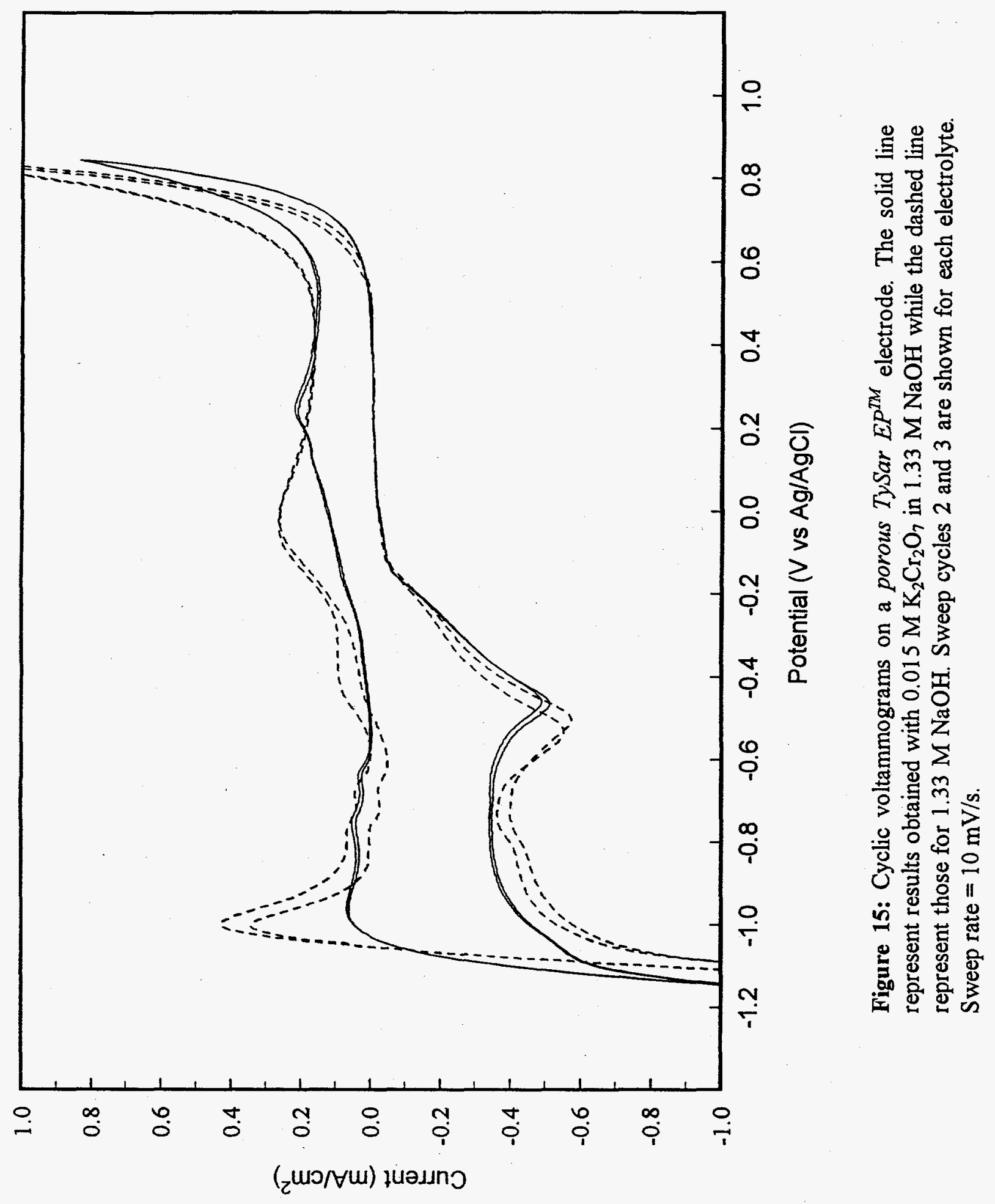




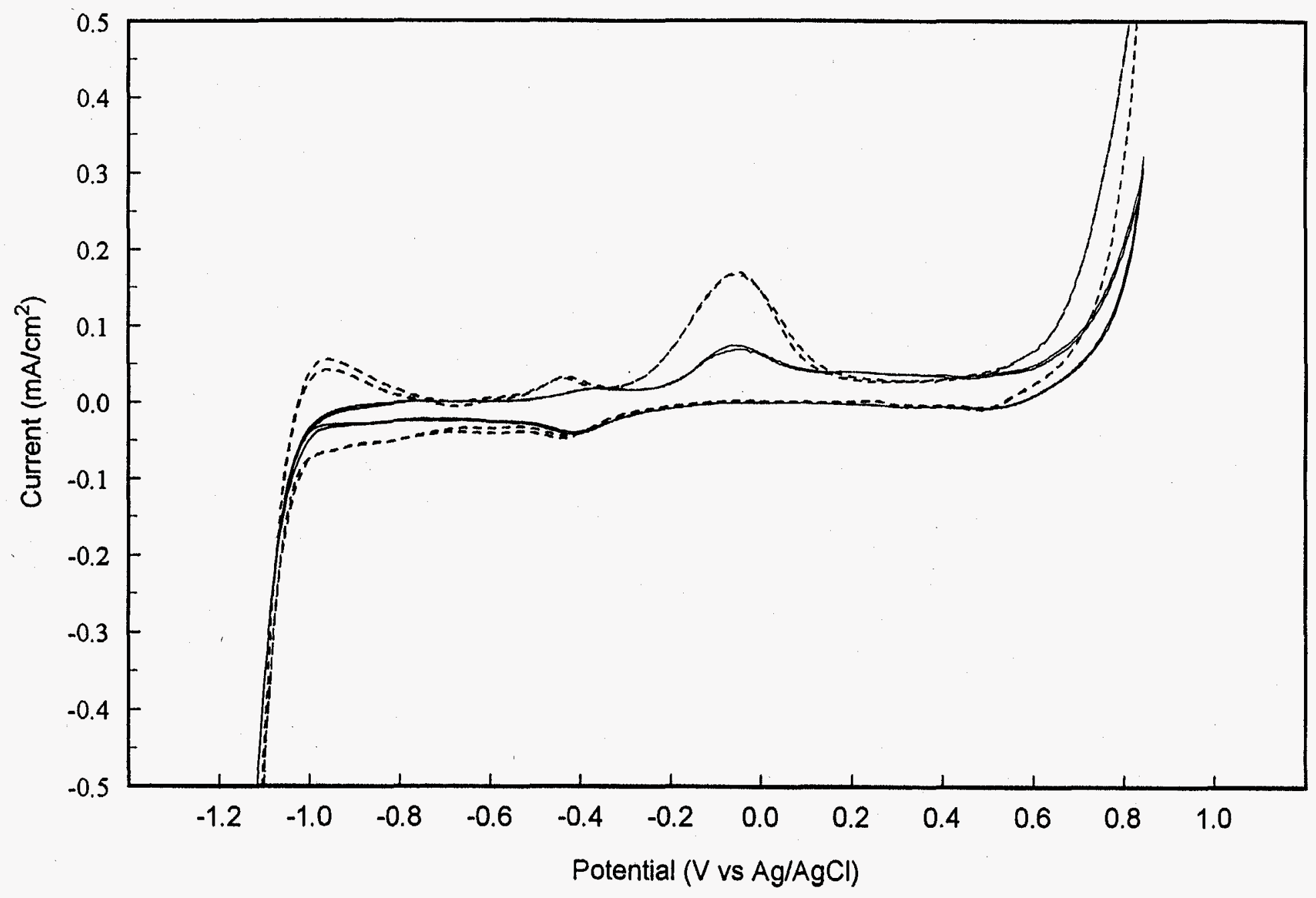

Figure 16: Cyclic voltammograms on a porous TySar $I M^{T M}$ electrode. The solid line represent results obtained with $0.015 \mathrm{M} \mathrm{K}_{2} \mathrm{Cr}_{2} \mathrm{O}_{7}$ in $1.33 \mathrm{M} \mathrm{NaOH}$ while the dashed line represent those for $1.33 \mathrm{M} \mathrm{NaOH}$. Sweep cycles 2 and 3 are shown for each electrolyte. Sweep rate $=10 \mathrm{mV} / \mathrm{s}$. 


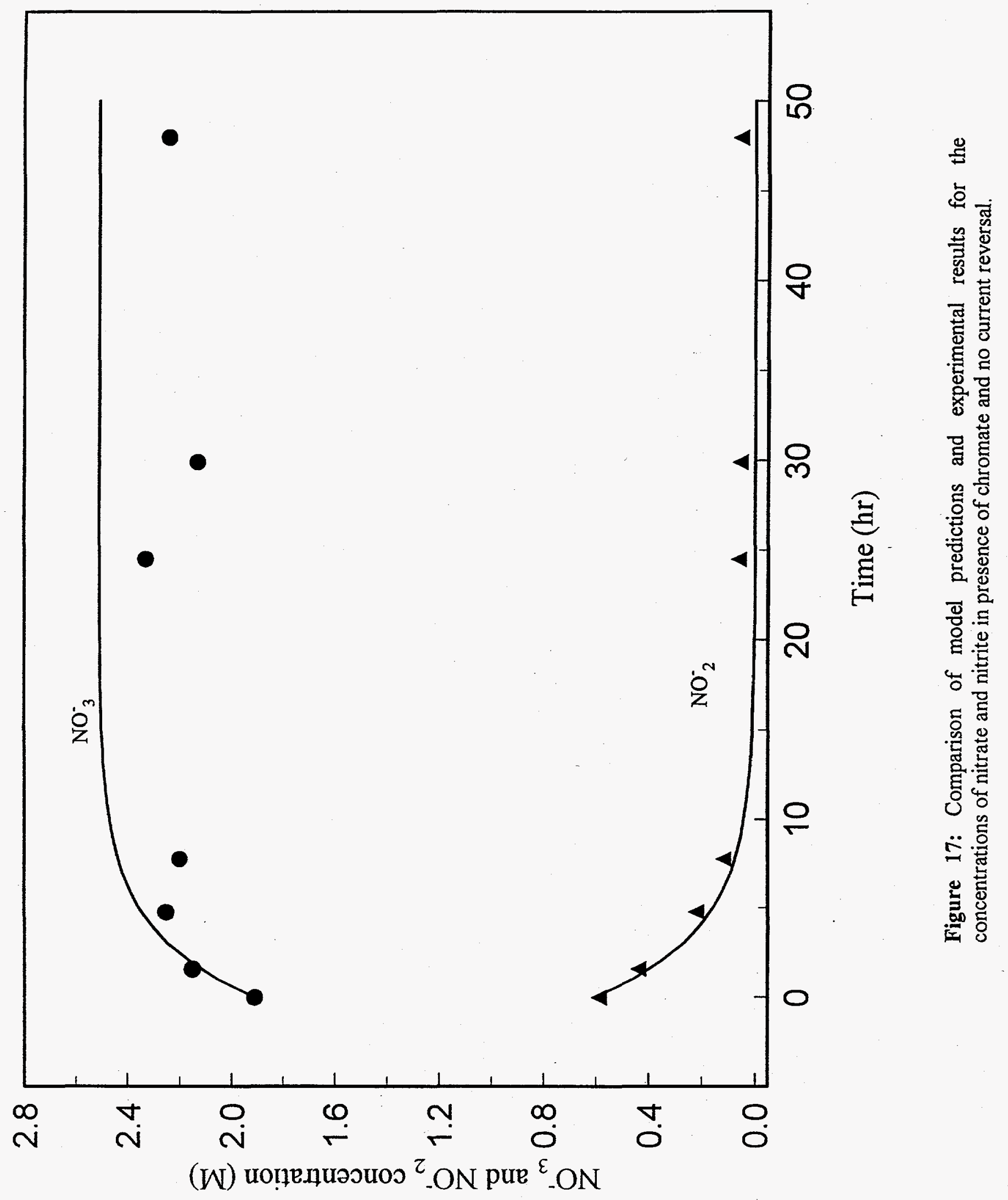




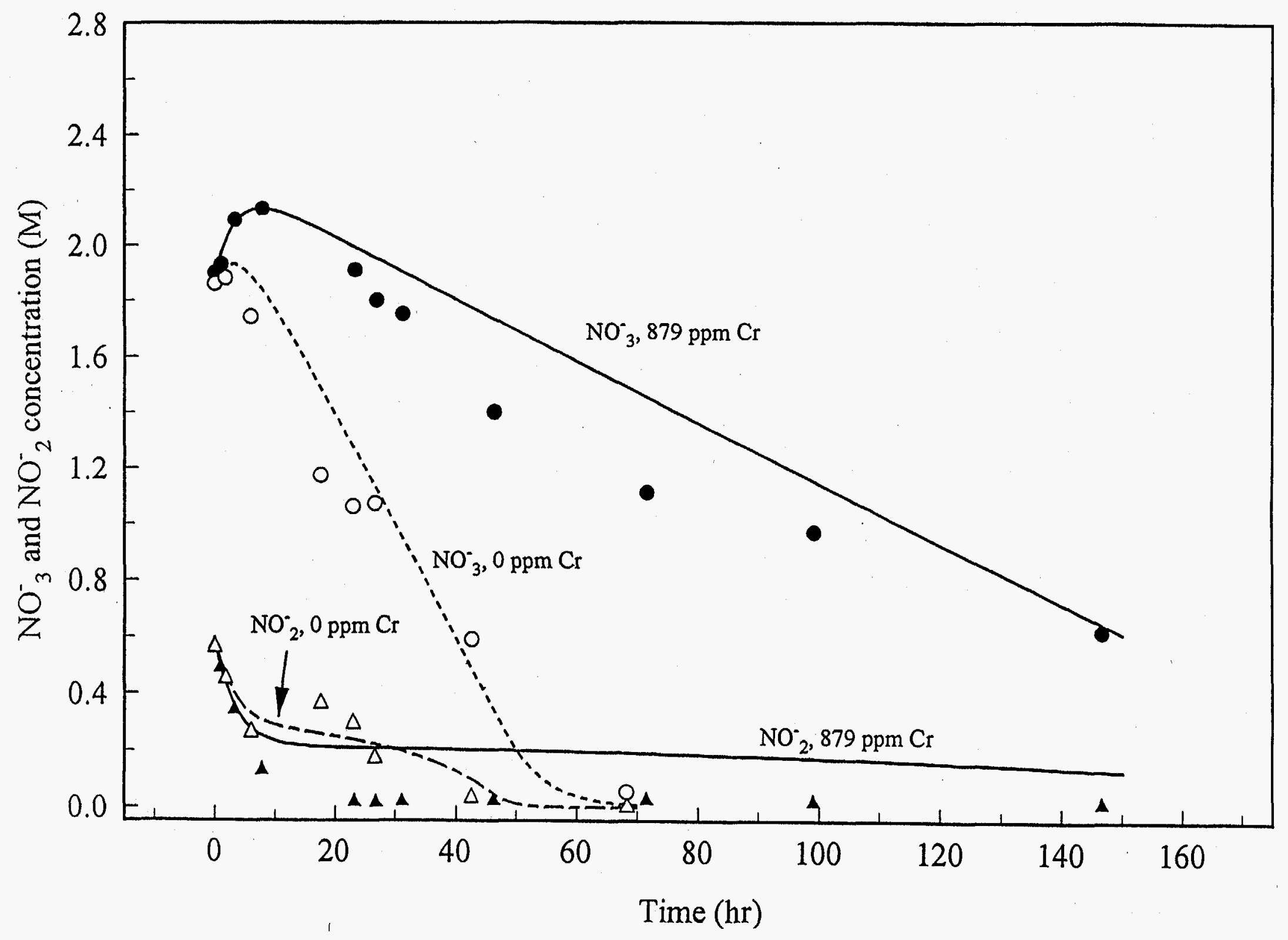

Figure 18: Comparison of model predictions and experimental results for the concentrations of nitrate and nitrite with and without chromate in the electrolyte. The solid lines and dark symbols represent model and experimental results for concentrations when $879 \mathrm{ppm}$ chromate is present and current is reversed every 30 minutes. The dashed lines and open symbols represent model and experimental results for concentrations when no chromate is present. 


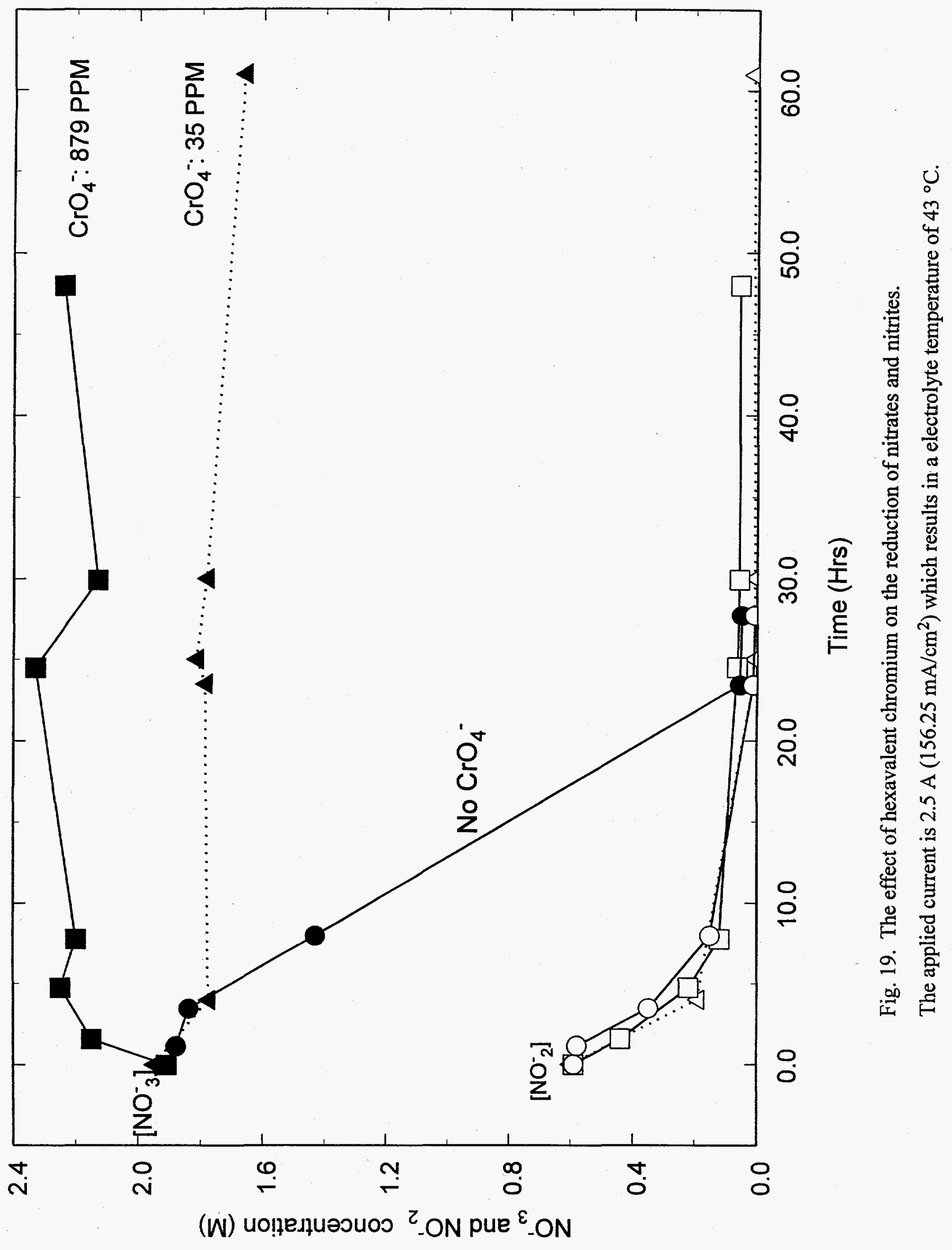




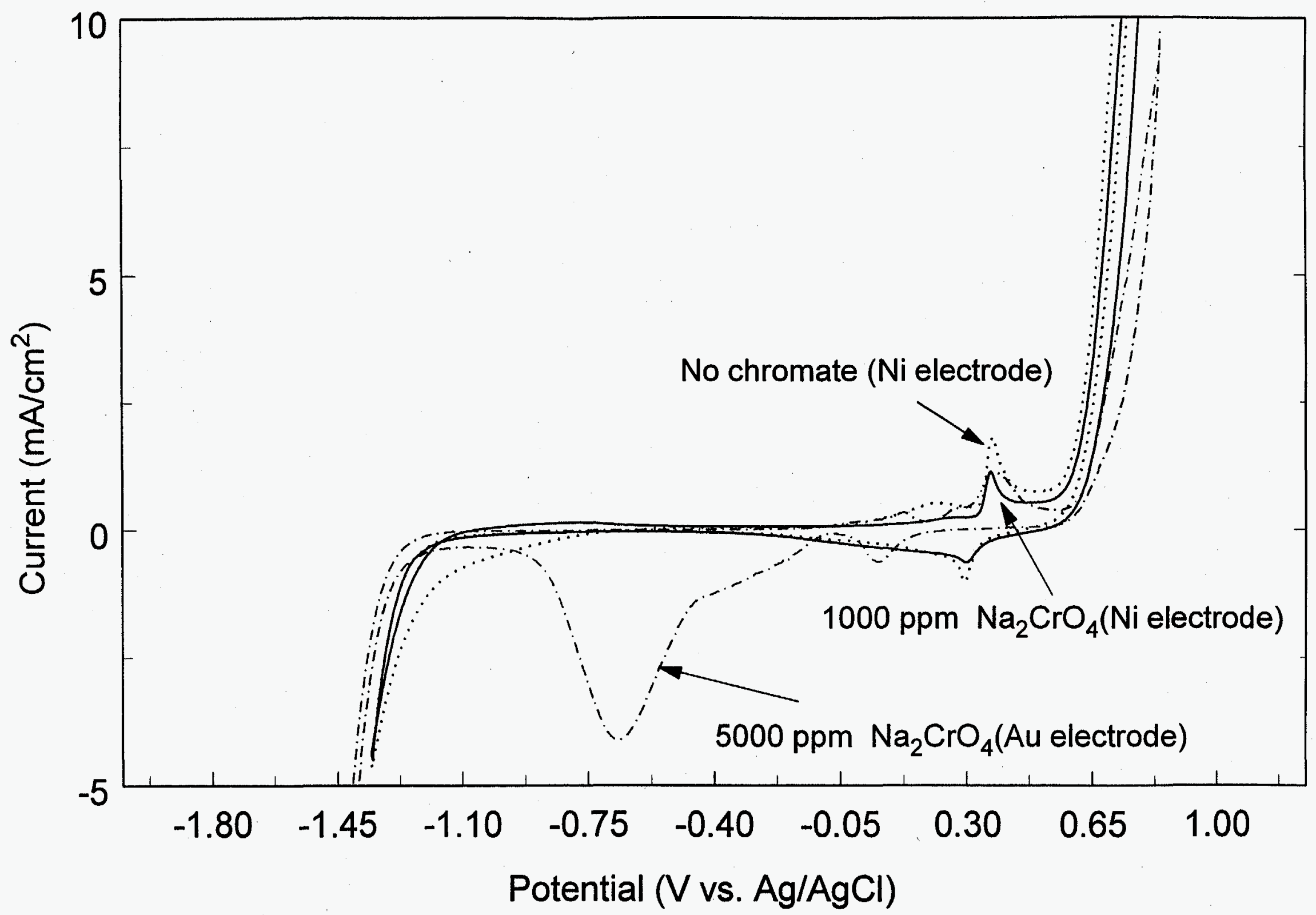

Fig. 20. Cycle voltammograms (CV) for hexavalent chromate on nickel and gold electrodes in 1.33 M KOH with and without chromate. The voltage range of the CVs was -1.3 to $0.7 \mathrm{~V}$ versus $\mathrm{Ag} / \mathrm{AgCl}$. Anodic currents are positive. 


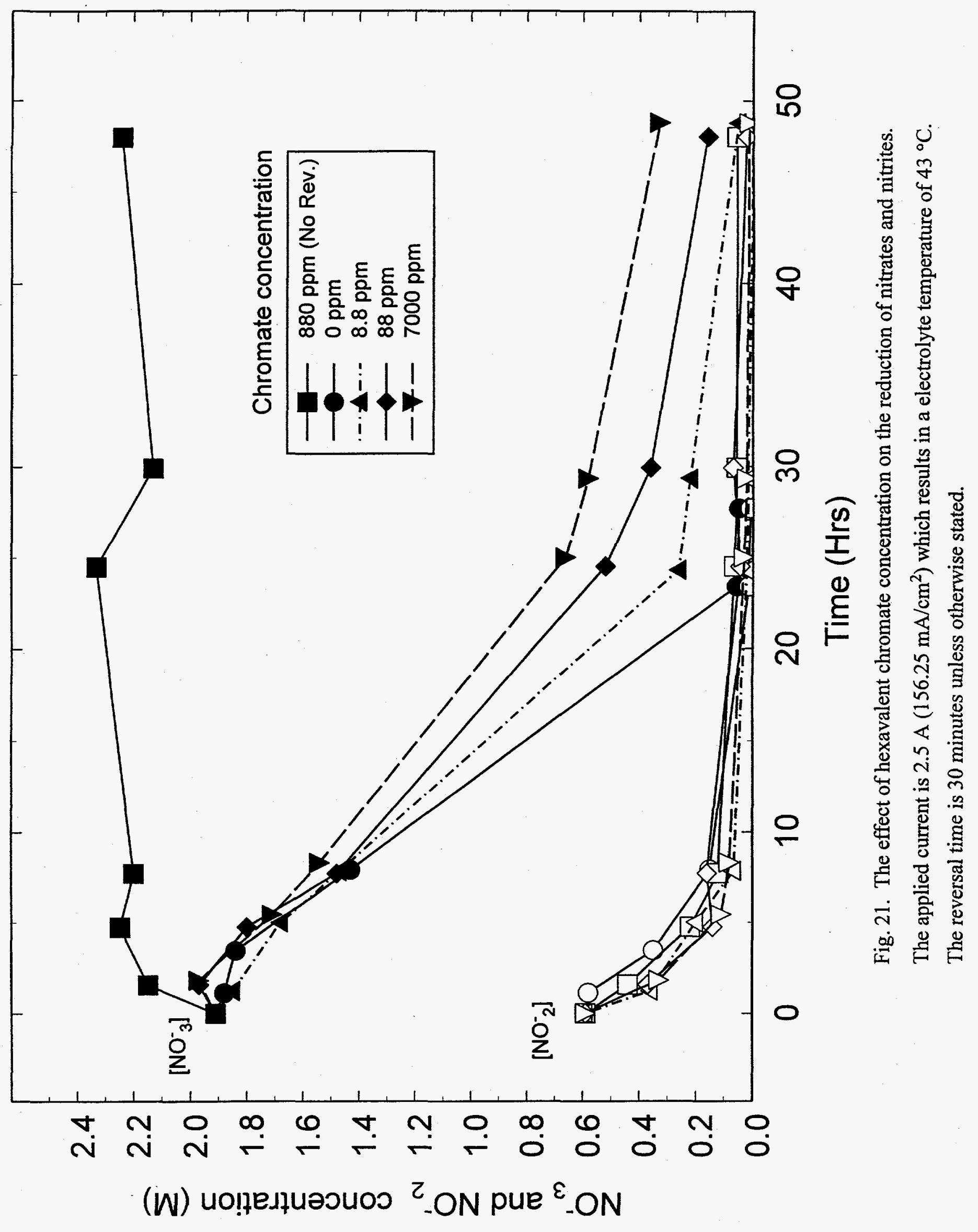




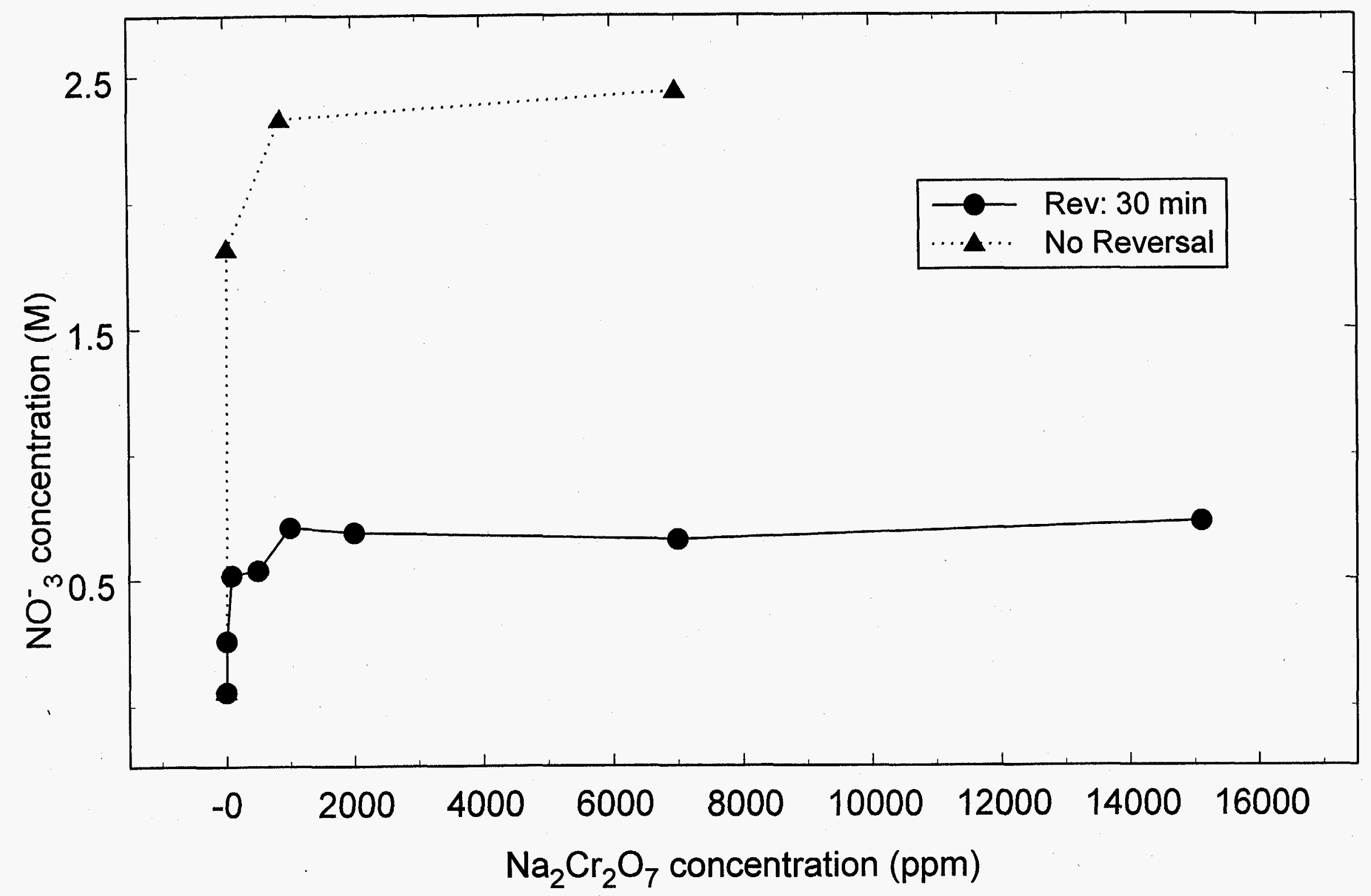

Fig. 22. Reduction of nitrates as function of the hexavalent chromate content with and without reversal of the electrode polarity. The nitrate concentrations plotted above correspond to 24 hours of operation. The initial nitrate and nitrite concentrations are $1.95 \mathrm{M}$ and $0.6 \mathrm{M}$, respectively. 


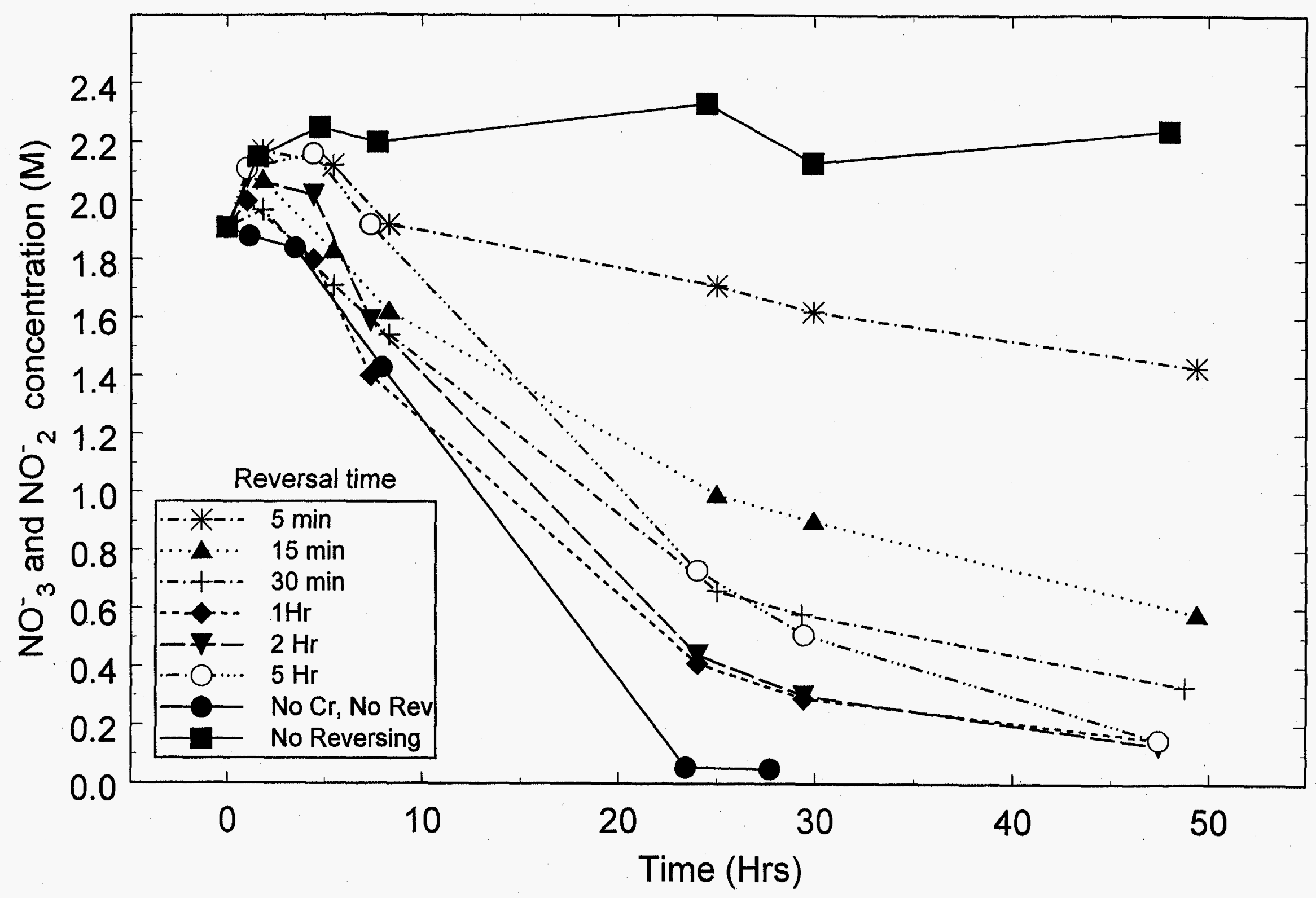

Fig. 23. The effect of different reversing times on the reduction of nitrates and nitrites. The applied current is $2.5 \mathrm{~A}\left(156.25 \mathrm{~mA} / \mathrm{cm}^{2}\right)$ which results in a electrolyte temperature of $43^{\circ} \mathrm{C}$.

The chromate concentration is $7000 \mathrm{ppm}$ unless otherwise stated. 


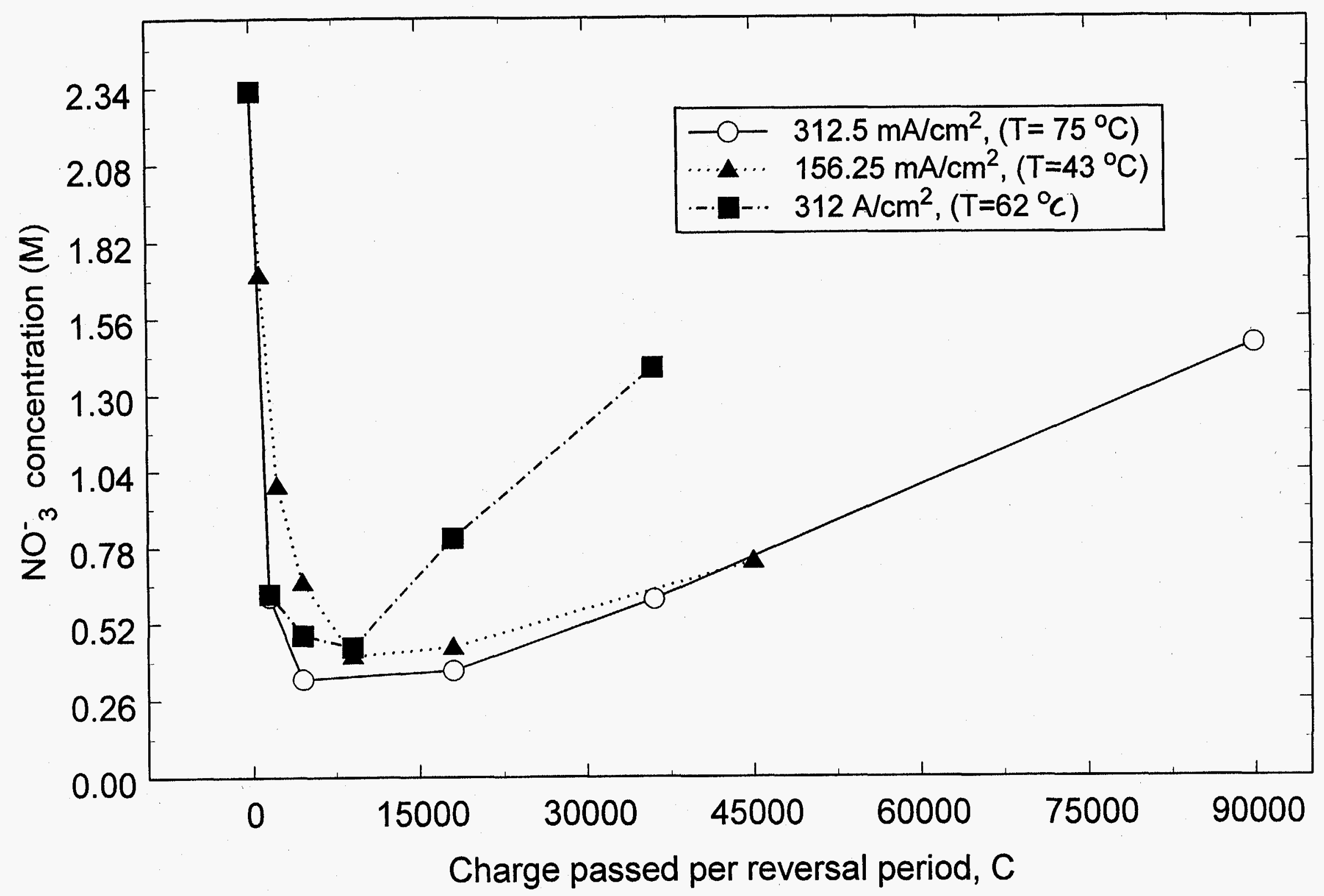

Fig. 24. Reduction of nitrates as a function of the charge per cycle. Charge per cycle is the amount of charge passed every time the electrode polarity is reversed. The average temperature for the run at $156.25 \mathrm{~mA} / \mathrm{cm}^{2}$ is $43^{\circ} \mathrm{C}$. For the experiments at $312 \mathrm{~mA} / \mathrm{cm}^{2}$, the average temperature is either $75^{\circ} \mathrm{C}$ or $62{ }^{\circ} \mathrm{C}$. 


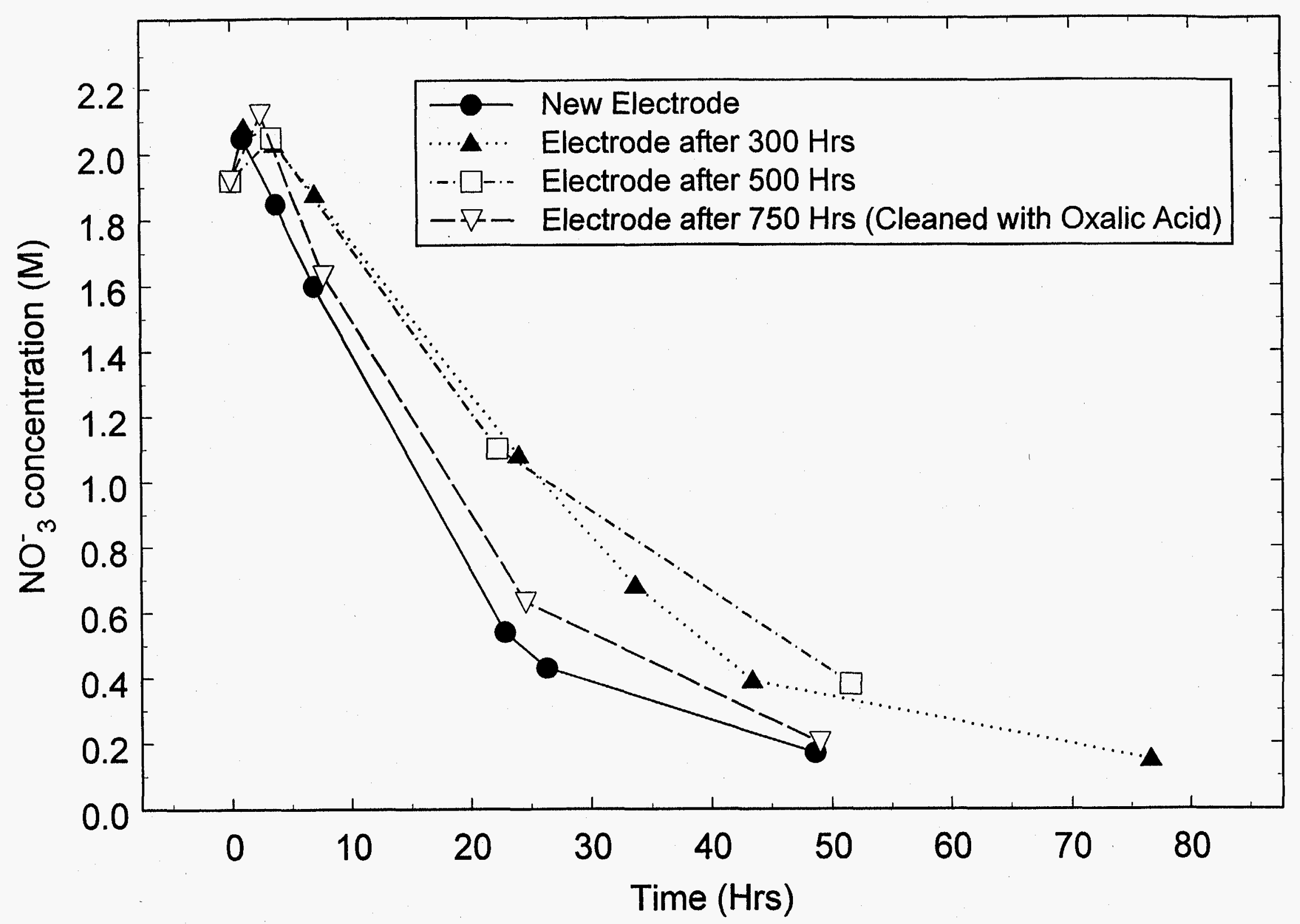

Fig. 25. The long-term performance of nickel electrodes run at $156.25 \mathrm{~mA} / \mathrm{cm}^{2}$ in an electrolyte containing 1.95 $\mathrm{M} \mathrm{NaNO} 3,0.6 \mathrm{M} \mathrm{NaNO} 2,1.33 \mathrm{NaOH}$ and $880 \mathrm{ppm}$ of Na2CrO4. Comparison is made among a new electrode, electrodes after 300 and 500 hours of operations and a set cleaned with oxalic acid after 750 hours of operation. 


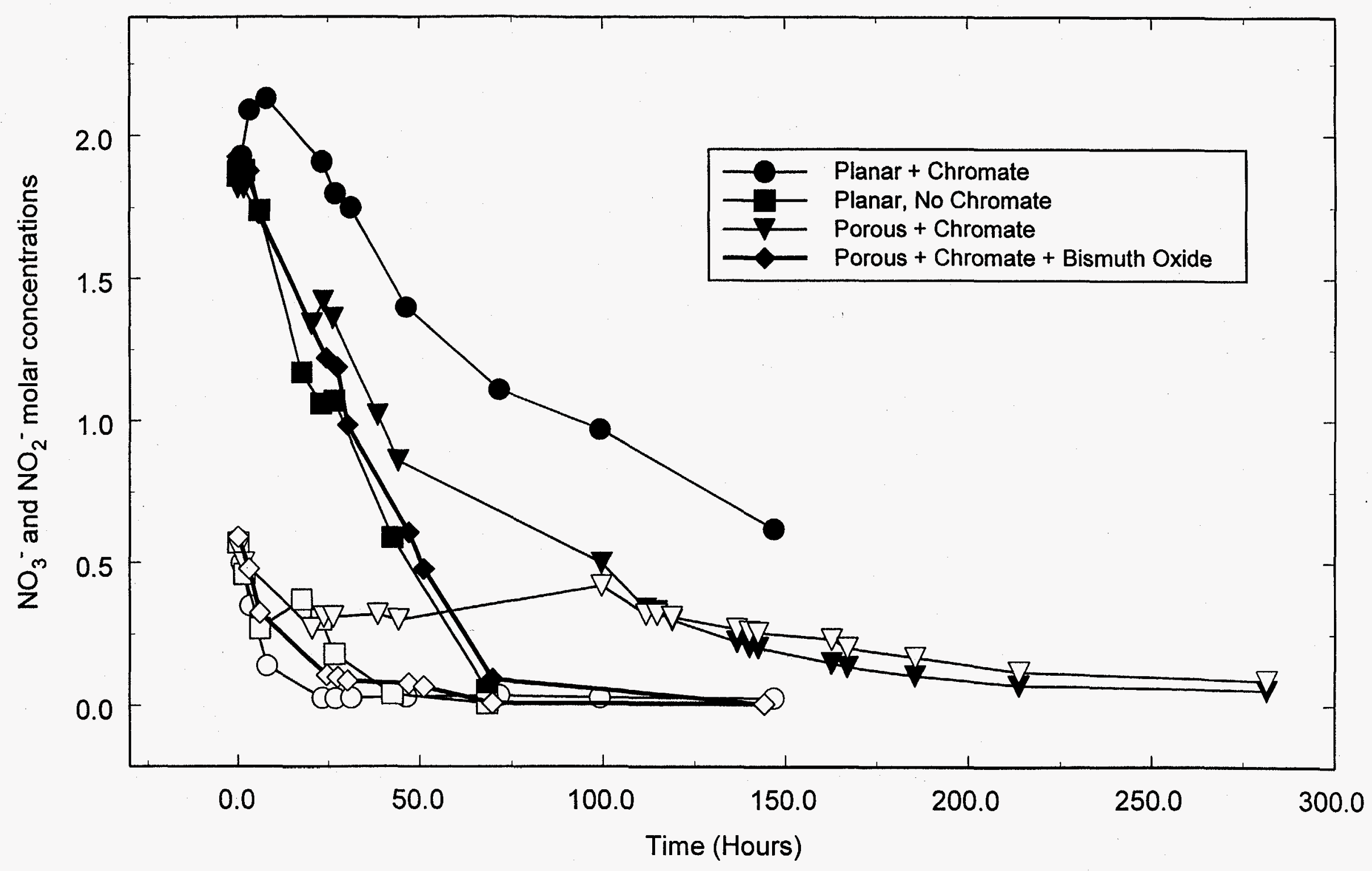

Fig. 26. Comparison of MP cell experiments with porous and planar electrodes. The electrode face area is $100 \mathrm{~cm}^{2}$, the applied current is $24.2 \mathrm{~A}$. The chromate and bismuth oxide concentrations are $1 \mathrm{~g} / \mathrm{L}$. 
Appendix 


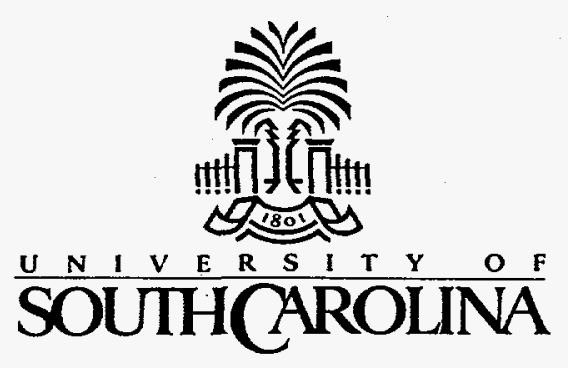

Department of Chemical Engineering College of EngineERING

Dr. David T. Hobbs

December 27, 1996

Bldg. 773-A

Westinghouse Savannah River Company

Aiken, SC

RE: Design Review, Task 2, of SCUREF Task Order 218

Dear David:

The purpose of this letter is to present the results of our design review of the Electrochemical Denitration and Caustic Recovery facility as specified in SCUREF Task order 218, Task \#2.

We reviewed Documents A through D listed below. We found the preliminary design described by these documents to be capable of processing between 1.7 and 2.3 million gallons per year of alkaline containing nitrate/nitrite waste. Based on the assumptions listed below, we calculated the destruction capacity and the energy and power requirements of the facility. This capacity depends on the sizes of the pumps used to fill and discharge the batch. As discussed below, the sizes of these pumps may need to be changed to meet the electrochemical cycle times. We based our calculation on the operation of eight of the ten electrolyzers. This allows for one spare electrolyzer in each of the two parallel flow loops. Our conclusions are:

The capacity of the facility depends on the concentrations of nitrate and nitrite in the waste stream. For example, if the concentrations of nitrate and nitrite are 2.2 moles/liter and 0.53 moles/liter respectively, the facility has an electrochemical capacity of 1.76 million gallons per year (MM gpy). On the other hand, if the concentrations of nitrate and nitrite are 1.68 moles/liter and 0.403 moles/liter respectively, the facility has an electrochemical capacity of $2.31 \mathrm{MM}$ gpy.

The batch time described under Note 4 of Document $C$, will vary depending on the concentrations. A batch time of 51 hours will be required for the higher concentrations (i.e., $1.76 \mathrm{MM}$ gpy). A batch time of 39 hours will be required for the lower concentrations (i.e., $2.31 \mathrm{MM}$ gpy). These times are not cycle times because they do not include the time to fill or empty the tanks labled TK-1 and TK-2. These times are based 
on a batch of 13,500 gallons and 274 days of electrolyzer operation. We do not know the specification for the delivery pump from Tank 50 and thus we cannot estimate the time required to fill Tank TK-1. However, pumps P-3 and P-4 are rated at 140 gpm which will require 1.7 hours to empty Tank TK-2. The size of these pumps are adequate and they do not significantly increase the cycle time.

The equipment tabulation on Document $C$ needs to list the quantity of pump P-1 as " 2 " rather than " 1 ". The flow rate of $1500 \mathrm{gpm} /$ pump would provide $300 \mathrm{gpm} /$ electrolyzer as stated in Document A if all ten electrolyzers are used. This flowrate will increase to 375 gpm when only eight electrolyzers are used. This flowrate should be sufficient provided that the electrode spacing yields a flow cross section of less than $3.2 \times 10^{-3} \mathrm{~m}^{2}$. This number is based on a linear velocity (past the electrode surface) of $0.11 \mathrm{~m} / \mathrm{s}$ used in our experiments and calculations from the MP cell. Future calculations and experimental work should verify the effect of flowrate (i.e., the mass transfer predictions) for the specific spacing in the FM21.

The power required to process these streams at the assumed rates is 2.61 million watts. The energy requirement is 17.2 million $\mathrm{kW}-\mathrm{hr} / \mathrm{yr}$. These numbers do not include the additional power and energy that will be required as a result of inefficiencies in the rectifiers. Pumping energy is also not included in this number.

As indicated in Document A, the cost of the rectifiers does not appear in Document B. The final design should consider a control scheme for the current which would minimize the generation of hydrogen toward the end of each batch run. This scheme would allow current densities four times larger (i.e., $1.4 \mathrm{~A} / \mathrm{m}^{2}$ ) at the beginning of the batch run. This control scheme may require multiple rectifiers. We have the capabilities to analyze the control scheme with the mathematical models developed in Wingard's dissertation.

We trust this summary is sufficient for your purposes. If you need further reviews or calculations, please call us.

Sincerely,

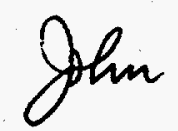

John W. Van Zee

Associate Professor 


\section{Assumptions and Calculation Basis}

1. The electrolyzers will be ICI FM 21-SP designed with 60 cells/electrolyzer.

2. The reaction area is $0.42 \mathrm{~m}^{2} /$ cell. This yields $25.2 \mathrm{~m}^{2}$ for each 60 cell electrlyzer.

3. Eight of the ten electrolyzers shown on the Piping and Instrumentation Diagram SK-M-001 will be used at any one time.

4. The reduction reactions are

$$
\begin{aligned}
& \mathrm{NO}_{3}^{-}+8 \mathrm{e}-+6 \mathrm{H}_{2} \mathrm{O} \Rightarrow \mathrm{NH}_{3}+9 \mathrm{OH}^{-} \\
& \mathrm{NO}_{2}^{-}+6 \mathrm{e}-+5 \mathrm{H}_{2} \mathrm{O} \Longrightarrow \mathrm{NH}_{3}+7 \mathrm{OH}^{-}
\end{aligned}
$$

Note that other nitrite reactions could be written with the products $\mathrm{N}_{2}$ and $\mathrm{N}_{2} \mathrm{O}$. However these reactions consume fewer electrons and thus the above reactions are conservative with respect to the specification of the power and energy requirements.

5 . The facility operates in a batch mode with a batch volume of 13,500 gallons. The electrochemical destruction part of the facility operates 274 days/yr. Additional time may be required to charge and discharge the batch.

6. Complete destruction of $\mathrm{NO}_{3}^{-}$and $\mathrm{NO}_{2}^{-}$occurs.

7. The cathodic reduction efficiency is $80 \%$.

8. The average current density is $3500 \mathrm{~A} / \mathrm{m}^{2}$.

9. The cells in each electrolyzer are monopolar and the cell voltage is 3.7 volts.

10. The cell voltage is based on an undivided cell.

11. The concentrations of nitrate and nitrite in the decontaminated salt solution from the Tank 50 transfer line range are: $\left[\mathrm{NO}_{3}{ }^{-}\right]=2.2 \mathrm{moles} / \mathrm{liter}$ maximum with $\left[\mathrm{NO}_{2}^{-}\right]=0.53 \mathrm{moles} /$ liter maximum and $\left[\mathrm{NO}_{3}{ }^{-}\right]=1.68 \mathrm{moles} /$ liter minimum with $\left[\mathrm{NO}_{2}^{-}\right]=0.40 \mathrm{moles} / \mathrm{liter}$ minimum.

\section{Reviewed Documents}

A. Letter No. ECS-105-96-0043 dated September 5, 1996 to D.T. Hobbs from Deepak Bhasin of Bechtel Savannah River, Inc.

B. The Estimate Summary Level Report dated August 23, 1996 with Log No. 96-05-06, R/1 consisting of 19 pages.

C. The Piping and Instrumentation Diagram No. SK-M-001, entitled "Electrolytic Denitration of Radio Active Waste Undivided Cell Process."

D. Drawing No. SK-A-002 showing the North and West Elevations and Sections A and B. This drawing is entitled "Nitration Reduction Facility" and it has a review date of 08/20/96. 